\title{
Ballasted track interaction effects in railway bridges with simply-supported spans composed by adjacent twin single-track decks
}

\author{
J.C. Sánchez-Quesada ${ }^{\mathrm{a}, *}$, E. Moliner ${ }^{\mathrm{a}}$, A. Romero ${ }^{\mathrm{b}}$, P. Galvín ${ }^{\mathrm{b}, \mathrm{c}}$, M.D. Martínez-Rodrigo ${ }^{\mathrm{a}}$ \\ ${ }^{a}$ Universitat Jaume I, Department of Mechanical Engineering and Construction, Avda. Sos Baynat s/n, ES-12071 \\ Castellón, Spain \\ ${ }^{b}$ Escuela Técnica Superior de Ingeniería, Universidad de Sevilla, Camino de los Descubrimientos s/n, ES-41092 Sevilla, \\ Spain \\ ${ }^{c}$ Laboratory of Engineering for Energy and Environmental Sustainability, Universidad de Sevilla, Camino de los \\ Descubrimientos $s / n$, ES-41092 Sevilla, Spain
}

\begin{abstract}
This paper is devoted to track-bridge interaction phenomena in railway bridges of short simply-supported (SS) spans composed by ballasted tracks. These structures may experience high vertical acceleration levels under operating conditions. In particular, the coupling effect exerted by the ballast track shared by structural parts that are theoretically independent, such as consecutive simply-supported spans or twin adjacent single-track decks, is investigated. Experimental evidence shows that in these cases there may be an important vibration transmission from the loaded to the unloaded track, and that the interlocked ballast granules couple some of the lowest modes of vibration to an important extent. To this end a detailed three-dimensional (3D) Finite Element (FE) model of an existing bridge is implemented where the ballast in weakly connected regions is simulated as transversely isotropic material, in order to represent in a simplified manner the degraded state due to the relative motion between the disconnected structural parts. First, the bridge numerical model is updated from the ambient vibration response of the structure previously measured by the authors. Second, a sensitivity analysis is performed on the properties of the degraded ballast and their effect on the first five modes of vibration of the bridge is discussed. Finally, the response of the bridge under operating conditions is computed numerically, compared with the response measured experimentally in the time and frequency domains and conclusions are extracted regarding the model adequacy.
\end{abstract}

Keywords: Railway bridges, track-bridge interaction, ballasted track, vertical acceleration, experimental measurements, resonance.

\footnotetext{
${ }^{*}$ Corresponding author.

Email address: jquesada@uji.es (J.C. Sánchez-Quesada)
} 


\section{Introduction}

The dynamic behaviour of railway bridges has been a matter of concern for scientists and engineers during the past decades. The periodic nature of the railway excitation, associated to the succession of identical passenger coaches and track components travelling at constant speed, may cause important vibration

5 levels in the infrastructure. Moreover, particular combinations of the structure natural periods and the train repetitive distances may induce resonance on the bridges, leading to a progressive increase of the vertical acceleration at the platform only bounded by the system damping. Bridges composed by simply supported spans are common in countries like Germany or China, as they may be constructed with rather systematic procedures, allowing prefabrication and partial replacement of the decks. In short-to-medium spans such structures are prone to experience resonance and important vertical vibrations due to their usually associated low mass and structural damping [1 4]. According to European Standards (EC) [5], the maximum vertical acceleration in railway bridges is limited to $3.5 \mathrm{~m} / \mathrm{s}^{2}$ for ballasted tracks, which constitutes a considerably restrictive requirement for the design of new structures.

In an attempt to predict accurately the bridge dynamic response under operating conditions several numerical models of different complexities have been proposed over the years. For practical purposes one major concern is to meet a compromise between accuracy, computational cost and the assumption of simplifications aligned with current regulations. The structural geometry and scheme of train loads are obvious and rather certain factors that affect the dynamic response significantly. In engineering consultancies it is common to admit a beam or plate-type behaviour for the bridge deck and to represent the railway excitation as constant moving loads, which is in accordance with the current standards and extensively used in the scientific literature [6 10]. However, other factors such as train-track-bridge and soil-structure interaction mechanisms are generally disregarded for practical applications, due to their uncertain nature and the computational effort usually required. The influence of such mechanisms on the bridge dynamics is the subject of study of a number of current investigations, and the work presented herein is specifically devoted to the coupling effect exerted by the ballasted track on bridges composed by SS spans and adjacent decks under operating conditions.

The ballasted track over a bridge distributes the axle loads from the rails to the structure, acts as a highfrequency filter and introduces a restraining effect at the end sections [11 14. In addition, experimental evidences of load and vibration transfer mechanisms between consecutive spans or adjacent SS decks sharing 
a continuous ballasted track have been reported over the last years [11 17. A vast description of different ballast models developed by researchers in the analysis of train-induced vibrations may be consulted in Reference [18]. These models fall into two main categories: discrete and continuous models. In discrete models the rail displacement is related to that of the bridge deck through a set of spring, damper and lumped mass elements generally defined at the sleepers positions that represent the stiffness, damping and mass of the different track components (sleepers, railpads, ballast and sub-ballast), while the rail is modelled as a continuous beam. From this basis, 2D and 3D representations of the track-bridge interaction have been reported in the scientific literature for different applications [11, 19 22. Discrete models are conceptually simple and require less computational effort than continuous models. However, it is difficult to obtain representative values for some of the track parameters. Also, they neglect potentially relevant aspects, such as the bending coupling between consecutive SS spans associated to the separation of the ballast and rails from the centre of gravity of the deck cross section, or the contribution of the ballast bed to the global deck stiffness. In 17 the authors describe the weak coupling observed between the successive SS spans of 45 a viaduct, and relate it to the proximity of the rails and the ballast to the center of gravity of the deck cross section. Also, the additional stiffness attributable to the ballast is evaluated in a truss railway bridge from experimental tests performed before and after the installation of the platform in 23 . The authors describe how the natural frequencies and mode shapes identified are affected by the additional ballast stiffness.

Continuous track models permit considering the composite action between the track and the bridge associated to the transmission of shear stress between the deck and the rails through the ballast. In these models, the ballast is generally represented as a continuum and is discretised into solid FE 24 26], admitting elastic and isotropic constant material properties. Additionally, in the ballast regions located at the joints between consecutive spans or decks, a few researchers propose the use of degraded material properties to take into account the possible loss of stiffness of the ballast due to the cyclic movement caused by passing trains $[27,28$. In these works, the degradation is accomplished by reducing the elastic modulus of the general ballast, which is considered elastic and isotropic. More refined techniques including the heterogeneous and granular nature of the ballast, such as the Discrete Element Method, are applied for the analysis of settlement and degradation under cyclic loading [29, 30], but they require enormous computational resources which make them unfeasible for the present application.

Models of ballasted tracks require a significant number of parameters which are highly uncertain. There- 
fore, a better understanding of their influence is needed in bridge engineering to develop more realistic and adequate numerical tools that, at the same time, do not fall into inadmissible computational costs. In this regard the performance of experimental campaigns on bridges, the development of appropriate calibration methodologies and the experimental-numerical validation becomes crucial. However, the number of reported field measurements performed on multi-span SS viaducts or bridges composed by adjacent decks only coupled through the ballast is scarce to derive general conclusions. Rebelo et al. [13] performed experimental tests on some single-span ballasted railway bridges composed by two adjacent single-track slabs and pointed out the existence of a coupling effect exerted by the shared ballast, which was especially relevant in skewed decks. This work was completed by Rigueiro et al. 11] with an investigation on different discrete modelling strategies for the track, which revealed a significant influence of the track model for frequency contributions higher than $15 \mathrm{~Hz}$, acting as a low pass filter. Chellini et al. 26 described an experimental campaign on two steel-concrete composite viaducts of the Torino-Milano high-speed (HS) line and highlighted the importance of considering the continuity of the track for an accurate calibration of the numerical models. Due to the high stiffness of the structures, the authors could reproduce reasonably well the bridge dynamic behaviour with a 3D FE numerical model of one single span by introducing artificial boundary conditions representing the restraining effect of the track at the supports. Also Liu et al. 17] obtained a fairly good prediction of the dynamic response of a multi-span SS viaduct under train passages modelling only a single span and including modified boundary conditions. Bonifacio et al. 28 analysed the dynamic response of a filler-beam railway bridge deck with several SS spans with single-track adjacent decks. A 3D FE model considering the ballast as a continuum was calibrated from the experimental response obtained under ambient vibration. The vertical displacement and acceleration response under the passage of the TGV train was numerically evaluated at the loaded and unloaded decks, showing a significant vibration transfer between them.

In the present work, the authors analyse the properties and coupling effect of the ballasted track taking as starting point Old Guadiana Bridge (Fig. 1), a representative railway bridge from a conventional railway line in Spain. The bridge is composed by two identical SS spans and two structurally independent but adjacent single-track decks. A clear dynamic coupling between the spans attributable to the track continuity, and also between the adjacent decks through the shared ballast layer was detected during experimental tests [15. This work aims to assess the extent of track-bridge interaction effects in such bridges and the key parameters affecting the dynamic coupling between structurally independent parts. With this purpose a 3D FE model is implemented. A degraded type of ballast with elastic anisotropic behaviour is assumed between 
subsequent spans or adjacent decks to represent the potential degradation due to the relative movements induced by railway traffic over these regions. The model is updated applying optimisation procedures to reproduce the modal properties identified experimentally. Then the influence of the main and degraded ballast properties is investigated by means of sensitivity analyses. Finally the bridge response under the passage of railway traffic is predicted and compared with experimental measurements in a view to assess the adequacy of the proposed numerical model.

The novelties and valuable contributions of the work presented herein are (i) the use of an anisotropic (transversely isotropic) material to account for ballast degradation induced by railway traffic close to the transverse and longitudinal structural joints; (ii) the development of a detailed sensitivity analysis on the degraded ballast properties in order to conclude which affect the most, what are the most influenced modal parameters and the extent of this influence; (iii) the optimisation of a numerical model that is able to reproduce with fairly good accuracy the response of up to five modes identified experimentally; (iv) the consideration of a real railway bridge which belongs to a conventional railway line as object of study. These structures are rather common and present considerably lower flexural stiffness, when compared to bridges specifically constructed for High-Speed services. Therefore, the contribution of the ballast track stiffness to the overall bending stiffness is expected to be significant; (v) providing experimental data of the response of this bridge, with a rather complex dynamic behaviour, both under resonant and not-resonant conditions.

\section{Old Guadiana Bridge}
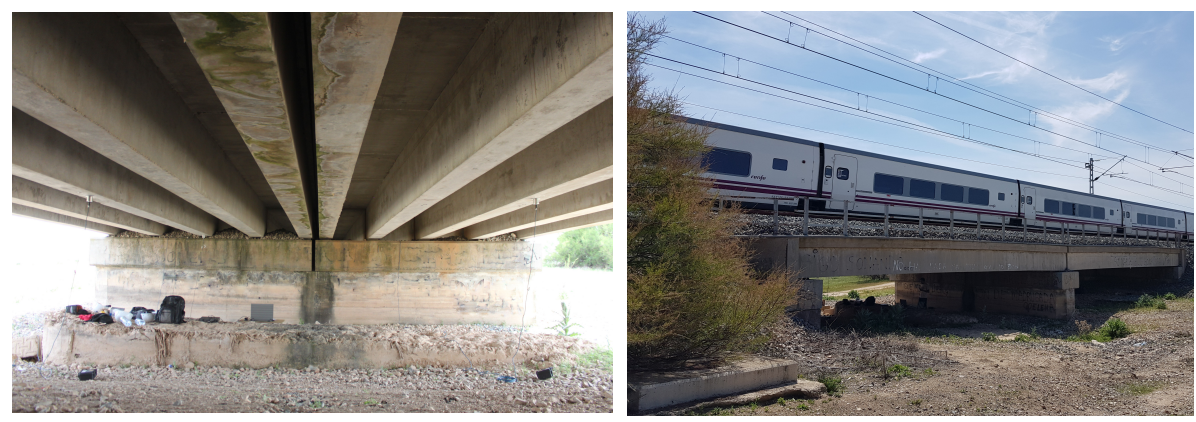

Figure 1: Old Guadiana Bridge: general view.

The structure under study is a double-track bridge that belongs to the conventional railway line MadridAlcázar de San Juan-Jaén in Spain (Fig. 1). It is composed by two identical SS spans of length $L=11.93 \mathrm{~m}$ 
single-track decks. Each deck is made of a reinforced concrete slab resting on five pre-stressed concrete girders (see Fig. 2). The decks are weakly connected along their longitudinal border through the ballast. Each track is conformed by Iberian gauge UIC60 rails and mono-block concrete sleepers separated $0.60 \mathrm{~m}$. The bridge sub-structure consists of two external abutments and one central support. The girders rest on them through laminated rubber bearings.

(a)

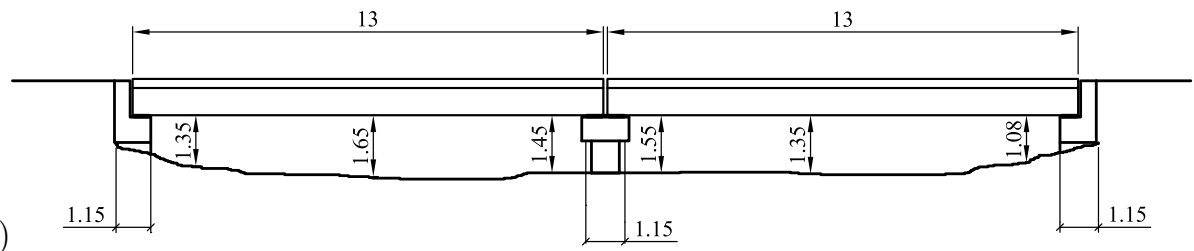

(b)

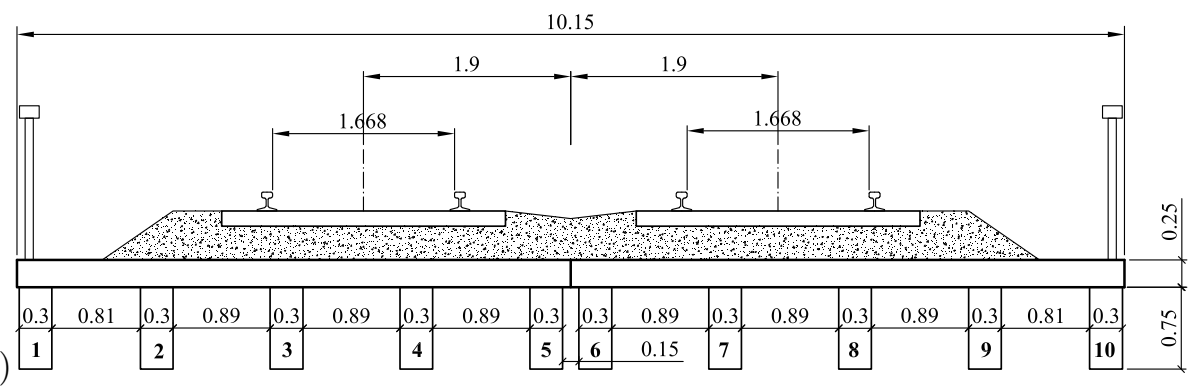

Figure 2: Old Guadiana Bridge: (a) elevation; (b) intermmediate cross-section

On May 2019 the response of the bridge was measured to characterise the modal parameters and the dynamic response under operating conditions. 18 accelerometers were installed underneath the girders and the vertical response was measured under ambient vibration and several train passages. The accelerometers were installed at points 1 to 18 indicated in Fig. 3. For details of the experimental campaign the reader is referred to Reference [15].

In Fig. 4 the first five experimental natural frequencies $\left(f_{i}^{e x p}\right)$, mode shapes and modal damping ratios $\left(\zeta_{i, A V}^{e x p}\right)$ identified from the ambient vibration response are included. Notice that the number of sensors installed was limited, especially in the second span. The lowest mode in frequency order corresponds to the first longitudinal bending mode of each span where the two adjacent decks vibrate in phase. In the second mode the two decks deform jointly creating a combined first torsion mode in each span. In the third mode, the two adjacent decks deform under independent torsion but out of phase conforming a first transverse bending mode. In the aforementioned modes, the coupling exerted by the ballast layer over the adjacent 


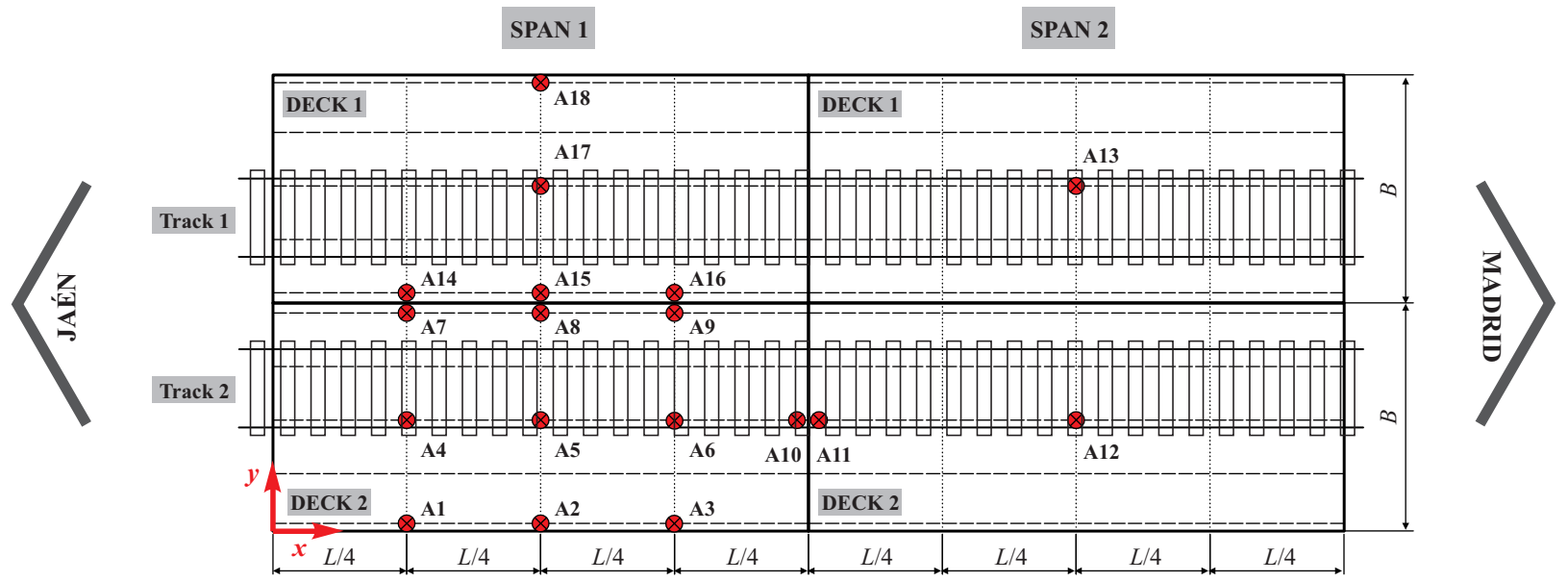

Figure 3: Sensors layout.

decks is evident. The fourth and fifth modes correspond to an in-phase torsional deformation and to the transverse bending of each deck, respectively.
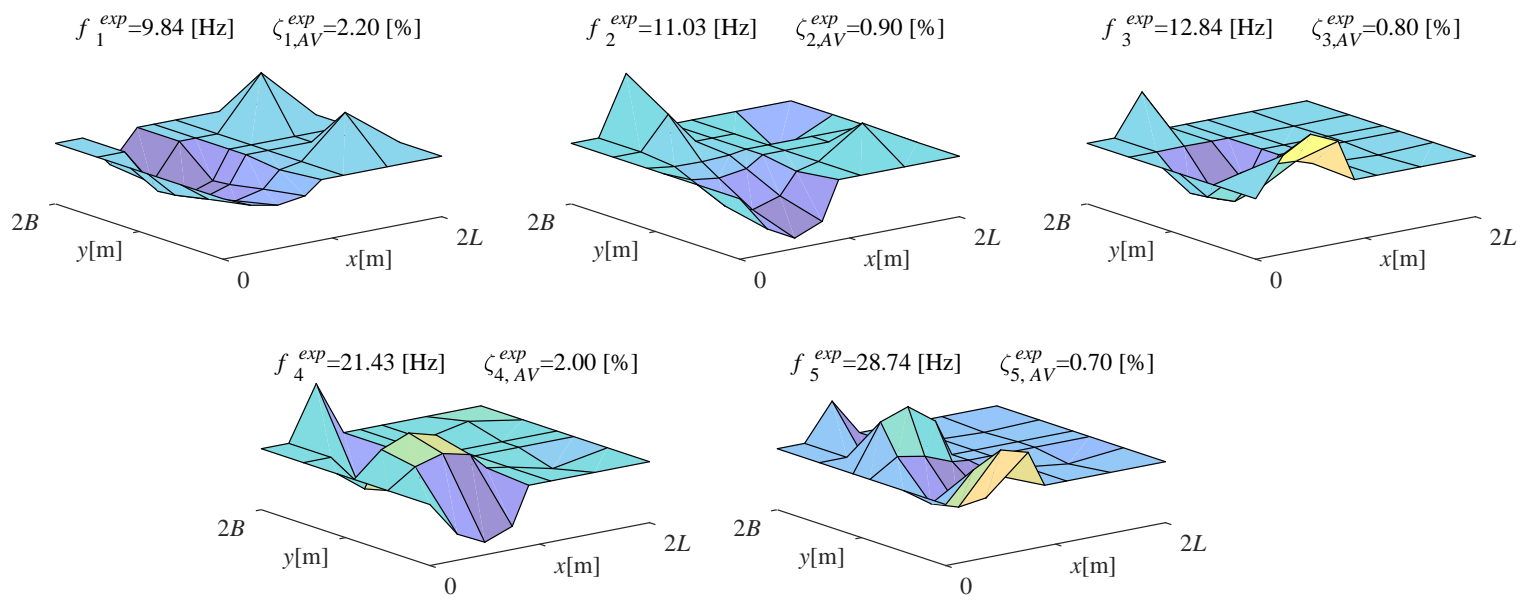

Figure 4: First five experimental modes, natural frequencies and modal damping ratios identified from ambient vibration.

\section{Numerical model}

\subsection{General description}

A 3D continuous track-bridge interaction model of the complete bridge is implemented in ANSYS(R)17.1.

The model includes the two spans and $15 \mathrm{~m}$ of the track over the embankment before and after the bridge (see Fig. 5). This additional track length is equivalent to 25 times the sleeper distance, which is considered 
adequate according to previous works [31, 32] and also to a convergence analysis performed in the present study. The slabs and longitudinal girders are modelled with shell FE (SHELL181) with 6 degrees of freedom (DOF) per node. The laminated rubber bearings at the girder supports are meshed with solid elements (SOLID185) with 3 DOF per node, considering their real dimensions $\left(w_{e b} \times l_{e b}\right.$ and thickness $\left.h_{e b}\right)$. The elastic modulus of the neoprene bearing isotropic material is estimated in order to reproduce the experimental static deflection measured during the proof load test in 2005 before the bridge opening [33. Each girder is connected to the bearings at the supports through kinematic constraints. A massless infinitely rigid plate is defined at the bearing top face in order to distribute the vertical force over the contact surface between both elements. As for the boundary conditions, the vertical displacement of the nodes at the horizontal lower surface of the bearings is restrained. As per the track model:

- The ballast layer is divided into (i) a main region meshed with solid elements (SOLID185) with isotropic elastic behaviour; and (ii) the volume of ballast in the vicinity of the longitudinal joint between the decks and along the transverse border between the two spans. In this last case the same solid elements are used but a transversely isotropic material behaviour is considered (see Fig. 5). With this approach it is intended to represent different interlocking mechanisms of the ballast granules in the out-of-plane (vertical) and in the in-plane (horizontal) directions, associated to the possible degradation in these regions.

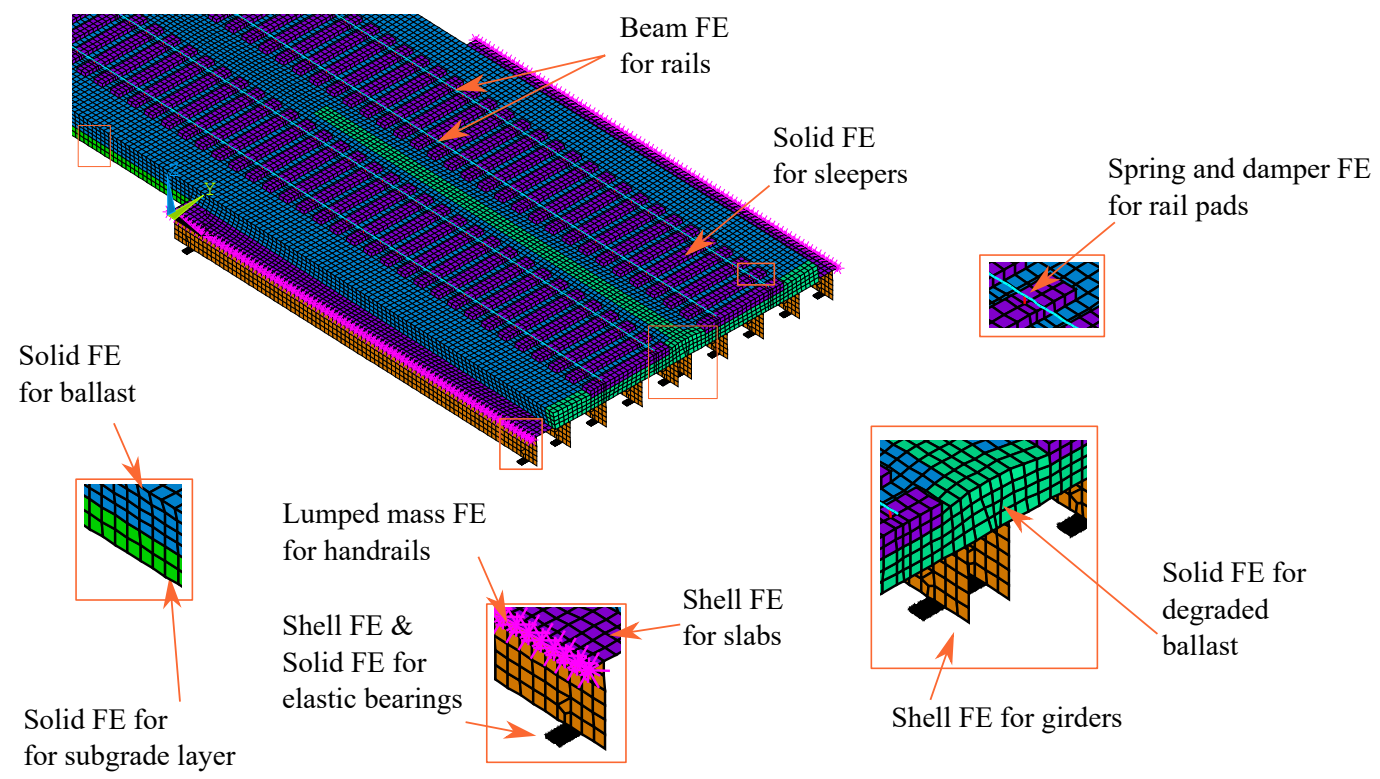

Figure 5: 3D track-bridge numerical model. In the view: detail of one span and track extension. 
- The sleepers are meshed into SOLID185 elements with elastic isotropic behaviour.

- The rails are modelled with Timoshenko beam elements with 6 DOF per node (BEAM188).

- For the rail pads discrete spring-dashpot elements (COMBIN14) with constant vertical stiffness and viscous damping $K_{p}$ and $C_{p}$, respectively, are adopted. These elements connect the relative vertical displacement between the rails and the sleepers. The vertical force transmitted by the rail pad element is distributed using kinematic constrains over the real contact area between both elements.

- Non-structural elements such as the handrails are included in the model as lumped masses (MASS21) uniformly distributed along the two external borders of the deck.

- In the $30 \mathrm{~m}$ of track extension on both sides of the bridge the ballast bed rests on a subgrade layer, which is also meshed with SOLID185 isotropic elastic elements. The three translations of the nodes at the horizontal lower plane of this layer are fully restrained.

The size of the FE mesh is refined so that the wavelengths of the modes up to $30 \mathrm{~Hz}$ are adequately reproduced. The final model consists of 231940 elements and 260210 nodes, which correspond to 769801 degrees of freedom.

\subsection{Model updating}

First, the numerical model is updated based on the modal parameters identified from the ambient vibration response of Old Guadiana Bridge. The correspondence between the experimental and numerical mode shapes is quantified through the Modal Assurance Criterion (MAC) [34 and the relative difference between the experimental and numerical frequencies of the paired modes as per:

$$
\mathrm{MAC}=\frac{\left(\Phi_{i}^{\text {exp }, \mathrm{T}} \cdot \Phi_{j}^{\text {num }}\right)^{2}}{\left(\Phi_{i}^{e x p, \mathrm{~T}} \cdot \Phi_{i}^{e x p}\right) \cdot\left(\Phi_{j}^{\text {num }, \mathrm{T}} \cdot \Phi_{j}^{\text {num }}\right)}
$$

180

$$
e_{100 \%}=\frac{f_{i}^{\text {exp }}-f_{j}^{\text {num }}}{f_{i}^{\text {exp }}} \cdot 100
$$

In the previous equations, $\Phi_{i}^{e x p}$ and $\Phi_{j}^{n u m}$ are the $i$-th and $j$-th experimental and numerical mode vectors, respectively, $f_{i}^{e x p}$ and $f_{j}^{\text {num }}$ the corresponding natural frequencies and "T" indicates transpose. 
An optimisation iterative procedure implemented in ANSYS-MATLAB (MATLAB(R)2017.b) is performed based on the minimisation of an objective function involving the difference in natural frequencies and MAC residuals. A genetic algorithm (GA) adapted from the one developed by Haataja [35] is adopted as the optimisation scheme, which is used to minimize the objective function

$$
\begin{aligned}
F_{o b j}(P) & =\sum_{i=1}^{3}\left|\frac{e_{100 \%, i, j}(P)}{100}\right|+\sum_{i=1}^{3}\left(1-M A C_{i, j}(P)\right) \\
P & =\left(E_{g}, \rho_{g}, E_{s}, \rho_{s}, \rho_{b}, E_{b X}, G_{b Y Z}\right)
\end{aligned}
$$

In Eq. 3(a), $|-|$ refers to the absolute value of the frequency difference $e_{100 \%}$ and $j$ stands for the numerical mode that is paired to the experimental counterpart $i$. The pairing strategy selects the numerical mode with the highest MAC number among the ones with frequency differences $\left|e_{100 \%}\right|$ lower than $10 \%$. The objective function is evaluated considering only the first three experimental modes which are expected to affect significantly the bridge dynamic response. With this strategy a satisfactory calibration for the first five experimental modes is achieved (see Table 2). In this work seven calibration parameters are selected for the minimisation of the objective function (Eq. 3(b)), which are explained in detail in what follows. The choice of the calibration parameters is based on a preliminary sensitivity analysis performed on the original FE model and to the level of knowledge and certainty on the track-bridge system properties.

Table 1 shows the model parameters used in the numerical idealisation of Old Guadiana bridge, in which the following nomenclature is used: $E, \nu$ and $\rho$ stand for the elastic modulus, Poisson's ratio, and mass density, respectively. Also, $X, Y$ and $Z$ refer to the longitudinal direction (parallel to the track), transverse and vertical directions, respectively. In the rail, $I_{y r}$ refers to the moment of inertia of the cross-section with respect to $Y$, and $m$ denotes linear distributed mass. Concerning the track components, the spring-dashpot discrete properties of the rail pads $\left(K_{p}\right.$ and $\left.C_{p}\right)$ are provided, and the sleepers dimensions (length, width and height) and total mass are designated as $l_{s l}, w_{s l}, h_{s l}$ and $M_{s l}$, respectively. As per the ballast properties, $h_{b}$ is the total height of the layer, which is assumed constant and uniform over the platform. Underneath the sleepers, the ballast thickness is $h_{b}-h_{s l} / 2$. A ballast thickness of $h_{b}=45 \mathrm{~cm}$ is considered based on in situ inspection, leading to a total ballast thickness underneath the sleepers of $34 \mathrm{~cm}$, in accordance with current 
Spanish regulations [36]. The influence of this parameter is particularly evaluated in subsection 4.1

\begin{tabular}{|c|c|c|c|c|c|c|}
\hline $\begin{array}{c}\text { Bridge } \\
\text { component }\end{array}$ & Notation & $\begin{array}{l}\text { Initial } \\
\text { value }\end{array}$ & $\begin{array}{l}\text { Optimization } \\
\text { range }\end{array}$ & $\begin{array}{l}\text { Final } \\
\text { value }\end{array}$ & Unit & Source \\
\hline \multirow{3}{*}{ Girders } & $E_{g}$ & $3.60 \cdot 10^{10}$ & {$[-30,+45] \%$} & $4.82 \cdot 10^{10}$ & $\mathrm{~Pa}$ & 37 \\
\hline & $\nu_{g}$ & 0.3 & - & 0.3 & - & \\
\hline & $\rho_{g}$ & 2500 & {$[-5,+5] \%$} & 2504 & $\mathrm{~kg} / \mathrm{m}^{3}$ & 37] \\
\hline \multirow{3}{*}{ Slabs } & $\overline{E_{s}}$ & $3.60 \cdot 10^{10}$ & {$[-30,+35] \%$} & $3.10 \cdot 10^{10}$ & $\mathrm{~Pa}$ & 37 \\
\hline & $\nu_{s}$ & 0.3 & - & 0.3 & - & \\
\hline & $\rho_{s}$ & 2500 & {$[-5,+5] \%$} & 2480 & $\mathrm{~kg} / \mathrm{m}^{3}$ & 37 , \\
\hline \multirow{3}{*}{$\begin{array}{c}\text { Elastic } \\
\text { bearings }\end{array}$} & $E_{e b}$ & $2.39 \cdot 10^{8}$ & - & $2.39 \cdot 10^{8}$ & $\mathrm{~Pa}$ & [19] \\
\hline & $\nu_{e b}$ & 0.2 & - & 0.2 & - & \\
\hline & $\rho_{e b}$ & 1230 & - & 1230 & $\mathrm{~kg} / \mathrm{m}^{3}$ & \\
\hline \multirow{3}{*}{$\begin{array}{l}\text { Rail } \\
\text { UIC60 }\end{array}$} & $E_{r}$ & $2.10 \cdot 10^{11}$ & - & $2.10 \cdot 10^{11}$ & $\mathrm{~Pa}$ & 38 \\
\hline & $I_{y r}$ & $3038 \cdot 10^{-8}$ & - & $3038 \cdot 10^{-8}$ & $\mathrm{~m}^{4}$ & 38 \\
\hline & $m_{r}$ & 60.34 & - & 60.34 & $\mathrm{~kg} / \mathrm{m}$ & 38 \\
\hline \multirow{2}{*}{ Rail pad } & $\overline{K_{p}}$ & $1.00 \cdot 10^{8}$ & - & $1.00 \cdot 10^{8}$ & $\mathrm{~N} / \mathrm{m}$ & 39 \\
\hline & $C_{p}$ & $7.50 \cdot 10^{4}$ & - & $7.50 \cdot 10^{4}$ & $\mathrm{Ns} / \mathrm{m}$ & [19] \\
\hline \multirow{6}{*}{ Sleeper } & $E_{s l}$ & $3.60 \cdot 10^{10}$ & - & $3.60 \cdot 10^{10}$ & $\mathrm{~Pa}$ & 40] \\
\hline & $\nu_{s l}$ & 0.3 & - & 0.3 & - & [40] \\
\hline & $w_{s l}$ & 0.30 & - & 0.30 & $\mathrm{~m}$ & [40] \\
\hline & $l_{s l}$ & 2.60 & - & 2.60 & $\mathrm{~m}$ & [40] \\
\hline & $h_{s l}$ & 0.22 & - & 0.22 & $\mathrm{~m}$ & [40] \\
\hline & $M_{s l}$ & 300 & - & 300 & $\mathrm{~kg}$ & [40] \\
\hline \multirow{4}{*}{ Ballast } & $h_{b}$ & 0.45 & - & 0.45 & $\mathrm{~m}$ & 36 \\
\hline & $E_{b}$ & $1.10 \cdot 10^{8}$ & - & $1.10 \cdot 10^{8}$ & $\mathrm{~Pa}$ & [19] \\
\hline & $\nu_{b}$ & 0.3 & - & 0.3 & - & [17] \\
\hline & $\rho_{b}$ & 1800 & {$[-30,30] \%$} & 1584 & $\mathrm{~kg} / \mathrm{m}^{3}$ & 37 ] \\
\hline \multirow{6}{*}{$\begin{array}{c}\text { Degraded } \\
\text { ballast }\end{array}$} & $E_{b X}=E_{b Y}$ & $1.10 \cdot 10^{8}$ & {$[-89,0] \%$} & $12.10 \cdot 10^{6}$ & $\mathrm{~Pa}$ & 27] \\
\hline & $E_{b Z}$ & $1.10 \cdot 10^{8}$ & - & $1.10 \cdot 10^{8}$ & $\mathrm{~Pa}$ & [27] \\
\hline & $G_{b Y Z}=G_{b X Z}$ & $4.58 \cdot 10^{7}$ & {$[-89,0] \%$} & $2.29 \cdot 10^{7}$ & $\mathrm{~Pa}$ & 27 ] \\
\hline & $\nu_{b X Y}=\nu_{b Y X}$ & 0.2 & - & 0.2 & - & [27] \\
\hline & $\nu_{b X Z}=\nu_{b Y Z}$ & 0.2 & - & 0.2 & - & [27] \\
\hline & $\rho_{b}$ & 1800 & {$[-30,30] \%$} & 1584 & $\mathrm{~kg} / \mathrm{m}^{3}$ & 37 \\
\hline \multirow{3}{*}{ Subgrade } & $E_{f}$ & $9.00 \cdot 10^{7}$ & - & $9.00 \cdot 10^{7}$ & $\mathrm{~Pa}$ & [19] \\
\hline & $\nu_{f}$ & 0.3 & - & 0.3 & - & \\
\hline & $\rho_{f}$ & 1800 & - & 1800 & $\mathrm{~kg} / \mathrm{m}^{3}$ & \\
\hline Handrail & $m_{h}$ & 50 & - & 50 & $\mathrm{~kg} / \mathrm{m}$ & \\
\hline
\end{tabular}

Table 1: Model parameters: initial values, ranges of variation and final values. 
Notice that the main ballast presents isotropic elastic properties $E_{b}$ and $\nu_{b}$, and that the degraded ballast elastic constants are expressed as $E_{b I}, G_{b I J}$ for the shear modulus, and $\nu_{b I J}$, where $I$ and $J$ refer to the spatial directions $X, Y$ and $Z$. The degraded ballast behaviour is considered transversely isotropic, therefore unequivocally defined by five independent elastic constants:

$$
E_{b X}=E_{b Y} \quad E_{b Z} \quad G_{b X Z}=G_{b Y Z} \quad \nu_{b X Y} \quad \nu_{b X Z}=\nu_{b Y Z}
$$

In Eq. 4. $E_{b X}=E_{b Y}$ are the in-plane elastic moduli; $E_{b Z}$ and $G_{b X Z}=G_{b Y Z}$ are the out-of-plane elastic and shear moduli, respectively, and $\nu_{b X Y}$ and $\nu_{b X Z}=\nu_{b Y Z}$ the Poisson's ratios.

The optimisation ranges of the calibration parameters updated by the GA scheme (Eq. 3(b)) are provided in Table 1 The choice of the lower and upper bounds for these variables is a crucial step in the model calibration. These ranges are selected based on engineering considerations, the associated level of uncertainty and the reference values found in the literature (Table 1). Specifically, no information was available about the concrete properties for the reinforced slab and prestressed girders of Old Guadiana Bridge. Therefore, a typical value for the elastic moduli $E_{g}$ and $E_{s}$ was adopted as initial guess and a wide range of variability was admitted. As a result, the final updated values are reasonable and in accordance to previous works cited in Table 1 . Concerning the ballast, three calibration properties were chosen $\left(\rho_{b}\right.$ and the degraded ballast elastic moduli), as their influence was found much more significant than the remaining ballast parameters. The preliminary sensitivity analysis performed on the uncalibrated FE model revealed the importance of considering degraded ballast regions with transversely isotropic material, since reaching a good correspondence with the experimental modal parameters required reducing the in-plane elastic constants $E_{b X}=E_{b Y}$ considerably in relation to $E_{b Z}$. Therefore, the elastic constants in the degraded regions were initially set to $E_{b X}=E_{b Y}=E_{b Z}$ (isotropic material) and successively reduced up to $0.11 \cdot E_{b Z}$ during the calibration procedure. This lower bound is the maximum feasible reduction of the elastic modulus to guarantee a positive definite elastic compliance matrix of the transversely isotropic material for Poisson's ratios $\nu_{b X Y}=\nu_{b Y X}=\nu_{b X Z}=\nu_{b Y Z}=0.2$. In a similar way, the constants $G_{b X Z}=G_{b Y Z}$ were initially set to $E_{b Z} /\left(2 \cdot\left(1+\nu_{b X Z}\right)\right)$ (isotropic material) and reduced up to $89 \%$ during the updating process. The influence of the cited degraded ballast material properties is discussed in detail in subsection 4.1. The final or updated values for the optimisation parameters are also given in Table 1 , which are obtained after several runs of the GA to guarantee the stability of the updating procedure, considering a population size of 70 (10 times the number of calibration parameters) and 200 generations. The crossover and mutation 
rate are set to 0.8 and 0.02 , respectively, the probability of tournament to 0.7 and the scale of mutation to 0.1 .

Table 2 shows the results of the model calibration in terms of numerical frequencies $\left(f_{j}^{\text {num }}\right)$, frequency differences $e_{100 \%}$, and MAC numbers of the paired numerical modes. In Table 3 MAC and frequency difference correlation matrices are included to demonstrate the mode pairing stability. In Fig. 6 the first five numerical mode shapes and natural frequencies of the updated model are presented. All the modes identified experimentally with natural frequencies below $30 \mathrm{~Hz}$ are finally reproduced numerically with reasonably good accuracy in terms of frequency differences and MAC numbers. The second and third modes, which are more affected by the continuity of the ballasted track between adjacent decks, are predicted with frequency differences lower than 5.5\%. Also their MAC numbers exhibit a satisfactory correlation with the measurements, with values close to 0.90 or even above. As can be seen the correspondence of the fifth numerical mode with the experimental measurements is less accurate in terms of both frequency and MAC number, which is reasonable considering the limited number of sensors available in the experimental campaign for an accurate identification of higher frequency modes.

\begin{tabular}{cccccc}
\hline Mode $(i)$ & 1 & 2 & 3 & 4 & 5 \\
\hline$f_{i}^{\text {exp }}[\mathrm{Hz}]$ & 9.84 & 11.03 & 12.84 & 21.43 & 28.74 \\
$f_{j}^{\text {num }}[\mathrm{Hz}]$ & 9.79 & 11.38 & 12.15 & 21.87 & 31.54 \\
$e_{100 \%}[-]$ & 0.47 & -3.17 & 5.37 & -2.05 & -9.75 \\
MAC [-] & 0.94 & 0.89 & 0.97 & 0.93 & 0.75 \\
\hline
\end{tabular}

Table 2: Experimental and numerical frequencies for modes under $30 \mathrm{~Hz}$. Frequency differences and MAC numbers of the paired modes after calibration

\begin{tabular}{|c|c|c|c|c|c|c|c|c|c|c|c|}
\hline & \multicolumn{5}{|c|}{$\begin{array}{c}\left|e_{\% 100}\right| \\
\text { Numerical modes }(\mathrm{j})\end{array}$} & \multicolumn{5}{|c|}{$\begin{array}{c}\text { MAC } \\
\text { Numerical modes (j) }\end{array}$} \\
\hline & & 1 & 6 & 7 & 17 & 19 & 1 & 6 & 7 & 17 & 19 \\
\hline \multirow{5}{*}{$\begin{array}{l}\text { Experimental } \\
\text { modes (i) }\end{array}$} & 1 & 0,47 & 15,70 & 23,51 & 122,26 & 220,59 & 0,94 & 0,00 & 0,00 & 0,00 & 0,37 \\
\hline & 2 & 11,25 & 3,17 & 10,13 & 98,18 & 185,87 & 0,09 & 0,89 & 0,01 & 0,10 & 0,02 \\
\hline & 3 & 23,74 & 11,35 & 5,37 & 70,29 & 145,64 & 0,00 & 0,07 & 0,97 & 0,05 & 0,00 \\
\hline & 4 & 54,30 & 46,88 & 43,29 & 2,05 & 47,20 & 0,00 & 0,01 & 0,05 & 0,93 & 0,02 \\
\hline & 5 & 65,93 & 60,39 & 57,72 & 23,91 & 9,75 & 0,19 & 0,00 & 0,02 & 0,16 & 0,75 \\
\hline
\end{tabular}

Table 3: MAC and frequency difference correlation matrices between experimental and numerical modes. 


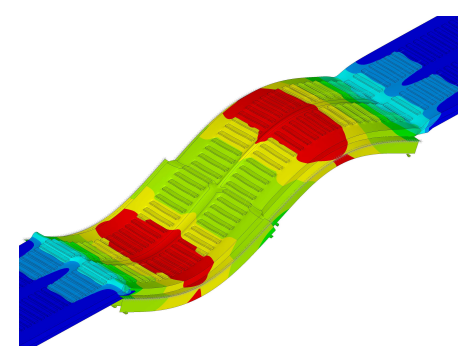

(a) $f_{1}^{\text {num }}=9.79 \mathrm{~Hz}$

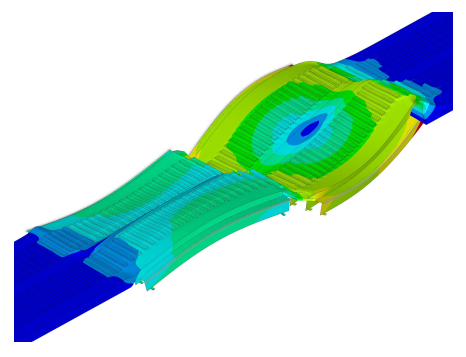

(b) $f_{2}^{\text {num }}=11.38 \mathrm{~Hz}$

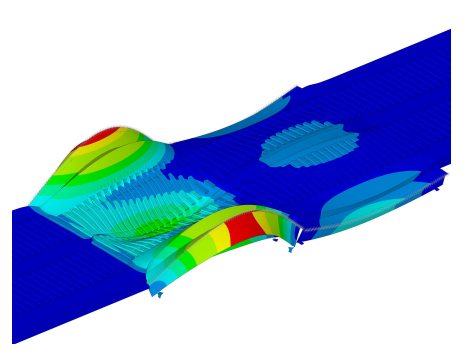

(c) $f_{3}^{\text {num }}=12.15 \mathrm{~Hz}$

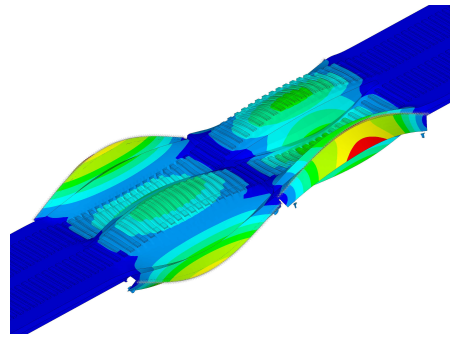

(d) $f_{4}^{\text {num }}=21.87 \mathrm{~Hz}$

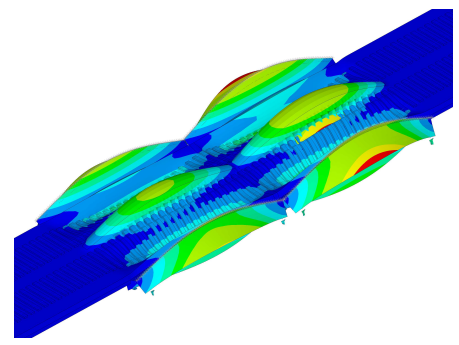

(e) $f_{5}^{\text {num }}=31.54 \mathrm{~Hz}$

Figure 6: Paired numerical mode-shapes and natural frequencies of the calibrated 3D model. 


\section{Sensitivity analysis on ballast properties}

\subsection{Evolution of modal parameters with degraded ballast elastic properties}

In this section a sensitivity analysis is presented in order to analyse the influence of the degraded ballast parameters on the frequency difference and MAC number of the paired modes. The parameters that are investigated are the elastic modulus in the vertical direction, $E_{b Z}$, the elastic modulus in the horizontal directions, $E_{b X}=E_{b Y}$ and the shear modulus in the $X Z$ and $Y Z$ planes, $G_{b X Z}=G_{b Y Z}$. The correspondence between experimental and numerical modes is evaluated for individual variations of the aforementioned properties. These variations are applied to the degraded ballast along the longitudinal shared border between the adjacent decks and along the transverse shared border between the two spans, separately. In Fig. 7 the MAC and frequency difference $e_{100 \%}$ are represented versus $E_{b Z}$ of the degraded ballast along the border between the decks for the five paired modes. In Fig. 8, the same quantities are represented but the degraded ballast property $E_{b Z}$ is modified only along the transverse border between the spans. In all the plots a dashed horizontal line indicates a zero difference between the numerical and experimental natural frequencies and a vertical dash-dot line points out the calibrated value of the elastic property. Similarly, in Figs. 9 and 10 and in Figs. 11 and 12 the same type of representations are included for the elastic modulus in the horizontal directions $E_{b X}=E_{b Y}$ and for the shear modulus in the $X Z$ and $Y Z$ planes $G_{b X Z}=G_{b Y Z}$, respectively. In all the cases, the model parameters are kept equal to their final updated value, except for the one that is modified.

From the analysis of the previous figures the following can be concluded:

- The first longitudinal bending mode is the one least affected by the degraded ballast elastic properties. As can be seen in the plots, the variations of the degraded ballast mechanical properties have a negligible effect on this mode.

- In order to obtain an acceptable difference for the second mode natural frequency (first torsion mode) the elastic modulus in the horizontal directions $E_{b X}=E_{b Y}$ must be substantially lower than the vertical elastic modulus $E_{b Z}$ (not higher than $20 \%$ of $E_{b Z}$ ), both along the longitudinal and the transverse borders. The MAC for this torsion mode is most affected by the value of the shear modulus in the $X Z$ and $Y Z$ planes, $G_{b X Z}=G_{b Y Z}$. The MAC number and frequency differences evolve in a similar way for variations of this parameter along both the longitudinal and the transverse borders. 
- The third mode (first transverse bending mode) is the one most affected by the degraded ballast elastic properties. In this case the frequency difference increases with the reduction of $E_{b Z}$ between the adjacent decks. This effect is also observed for the fourth mode. Nevertheless, the influence of this parameter is not very significant. A minimum value of the elastic modulus in the horizontal directions $E_{b X}=E_{b Y}$ both between the decks and between the spans is needed for the numerical model to reproduce the experimental third mode, opposite to what happens with the torsion mode. Then, for values higher than $40 \mathrm{MPa}$ along the longitudinal border, the model becomes too rigid and the frequency difference is unacceptable. That is not the case for the degraded ballast between the spans. As for the shear modulus $G_{b X Z}=G_{b Y Z}$, the value of this parameter does not affect much the $\mathrm{MAC}$ of the third mode but the frequency correspondence improves with the increase of this property in the vicinity of the calibrated value. between the twin decks is more noticeable than between the spans. Nevertheless, the subsequent alteration of the boundary conditions is significant for the second and third modes appropriate representation. 

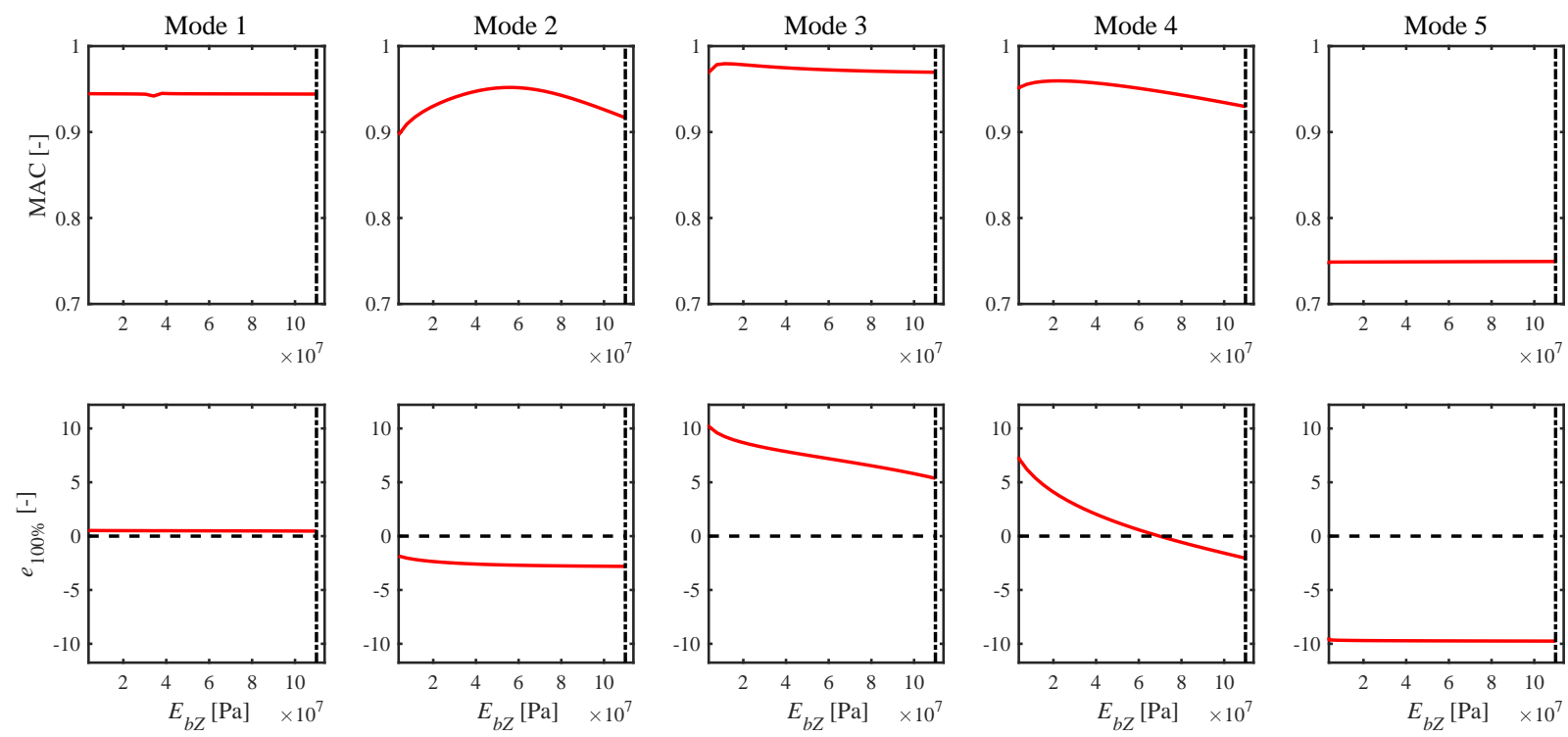

Figure 7: Modal parameters variation in terms of $E_{b Z}$ of the degraded ballast along the longitudinal border between adjacent decks.
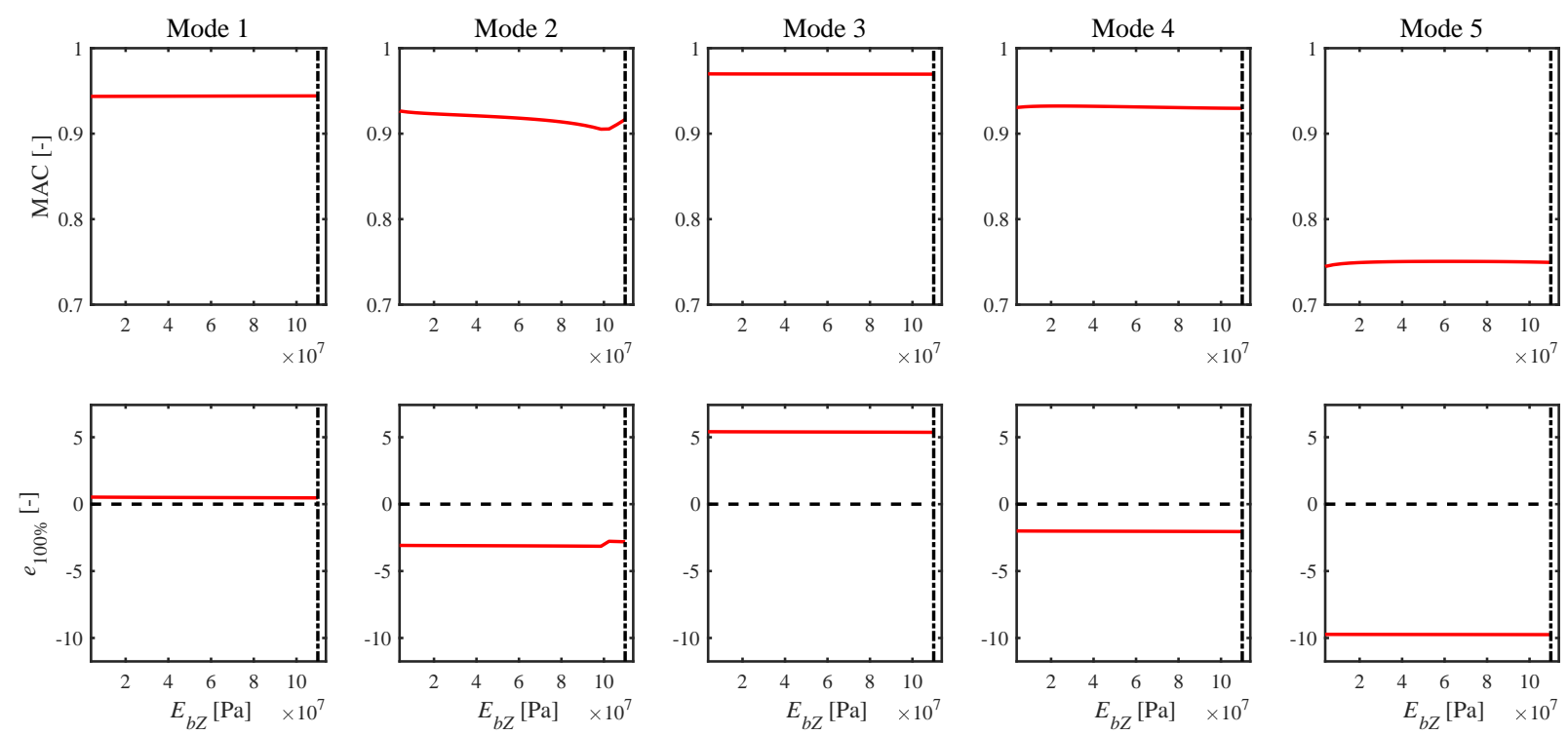

Figure 8: Modal parameters variation in terms of $E_{b Z}$ of the degraded ballast along the transverse border between spans. 

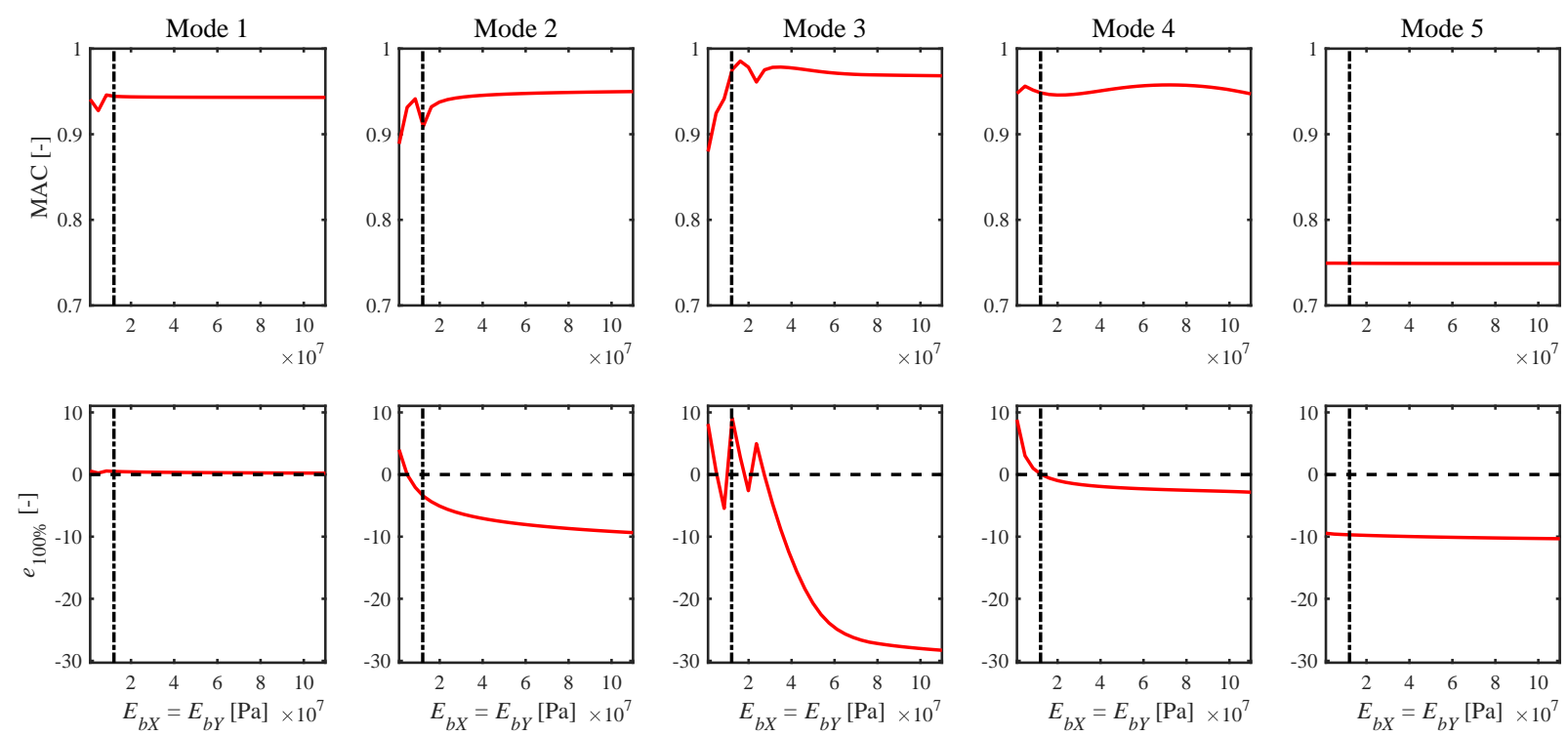

Figure 9: Modal parameters variation in terms of $E_{b X}=E_{b Y}$ of the degraded ballast along the longitudinal border between adjacent decks.
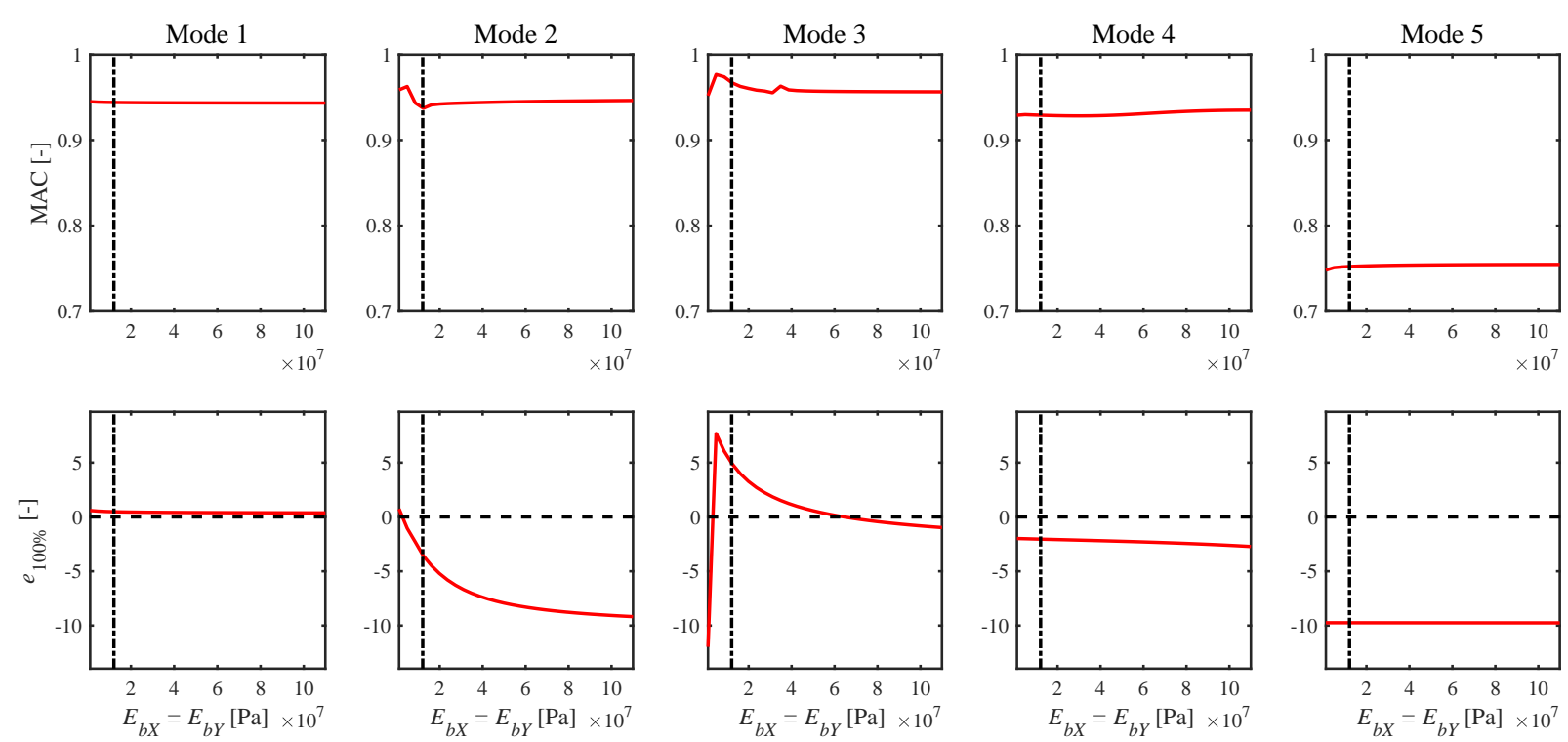

Figure 10: Modal parameters variation in terms of $E_{b X}=E_{b Y}$ of the degraded ballast along the transverse border between spans. 

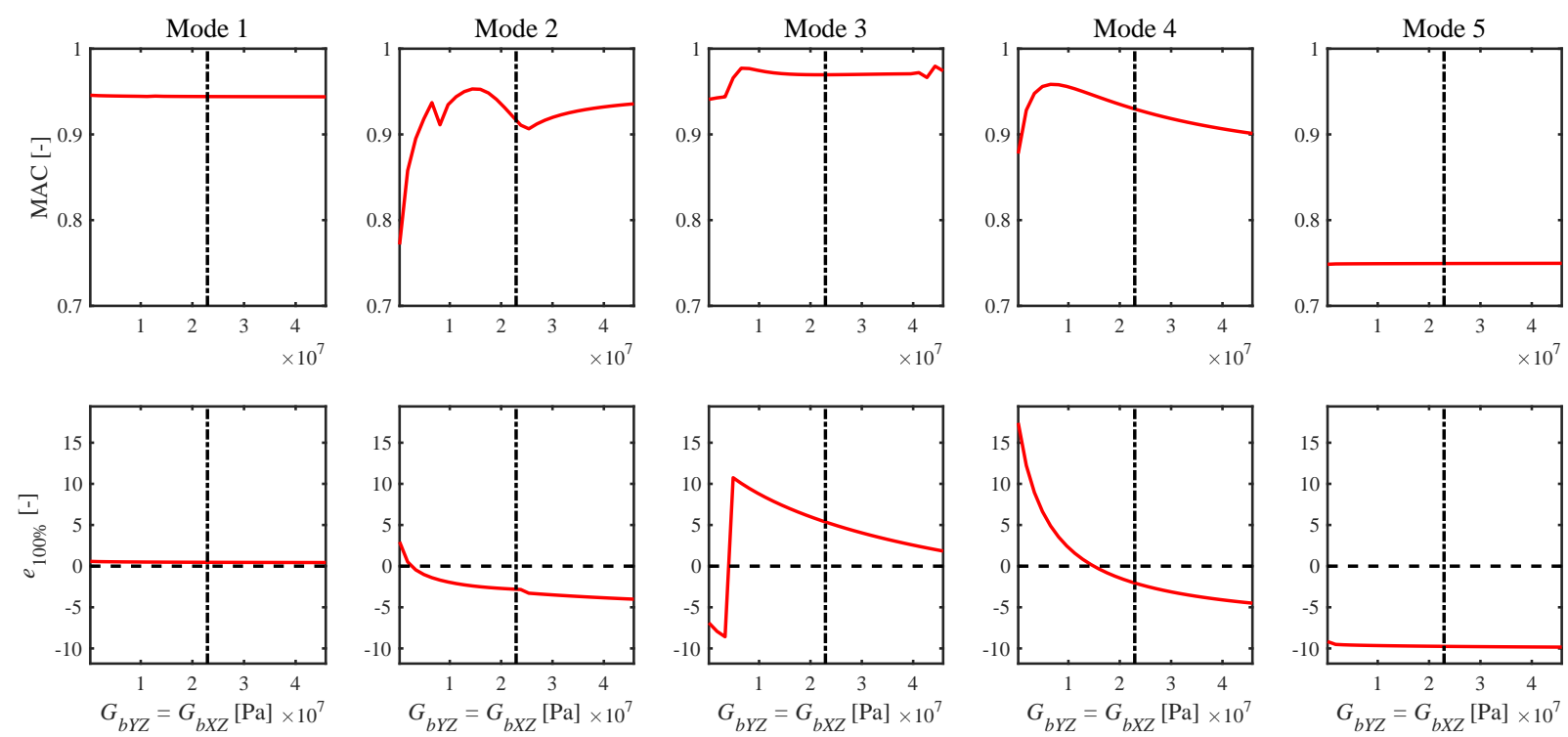

Figure 11: Modal parameters variation in terms of $G_{b X Z}=G_{b Y Z}$ of the degraded ballast along the longitudinal border between adjacent decks.
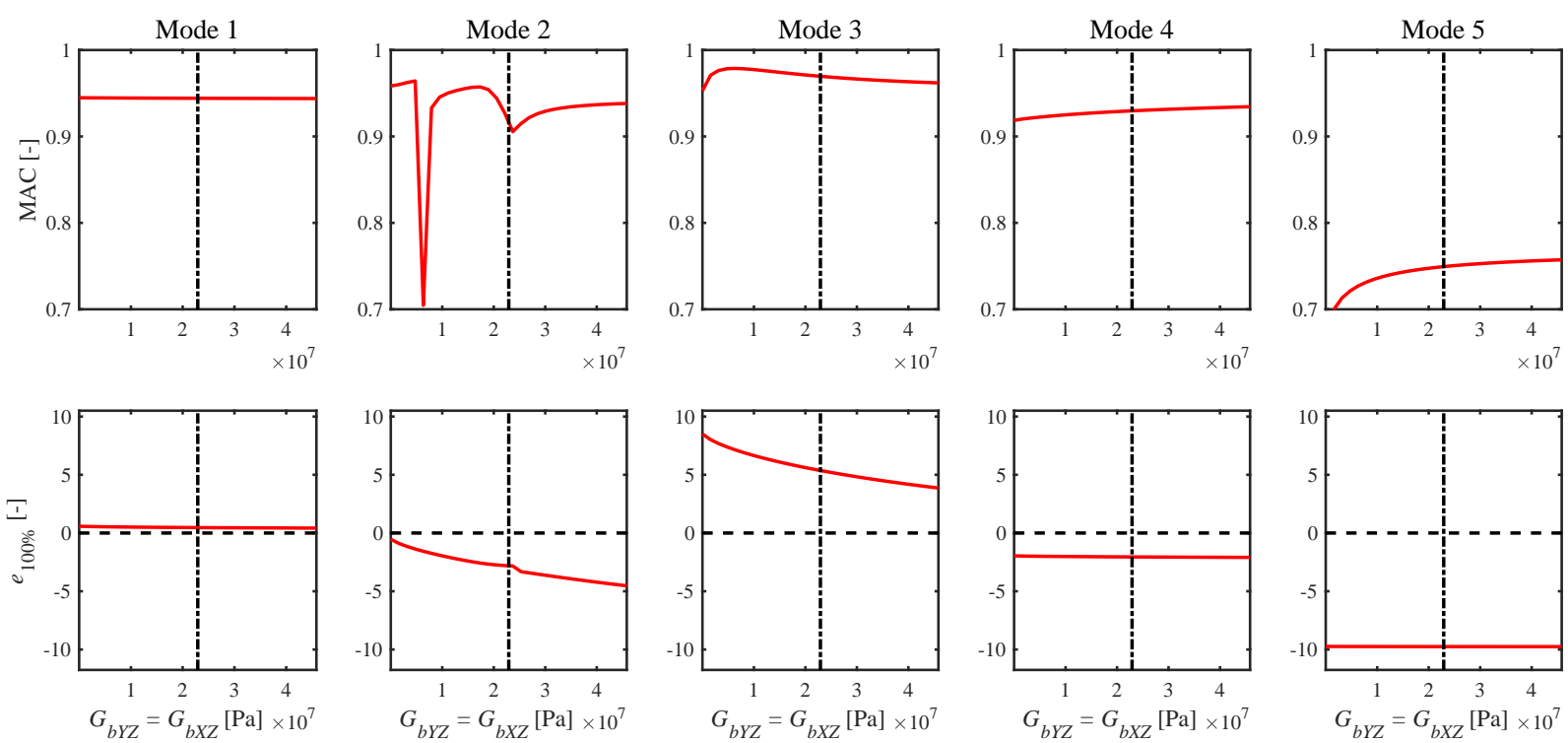

Figure 12: Modal parameters variation in terms of $G_{b X Z}=G_{b Y Z}$ of the degraded ballast along the transverse border between spans. 


\subsection{Evolution of modal parameters with thickness of the ballast layer}

Finally, in this subsection the influence of the thickness of the ballast layer on the modal numericalexperimental correspondence is evaluated. In Fig. 13 the same type of representations as in the previous subsection are included for the evolution of the MAC and $e_{100 \%}$ value for the five paired modes in terms of the ballast thickness $h_{b}$. The same thickness is assumed for both the main and the degraded ballast regions, based on in situ observations. The rest of the model parameters are kept unmodified and equal to their final updated values. In order to be able to separate the effect of the added mass and the added stiffness that the increase of $h_{b}$ entails, two different results are provided. On the one hand, the total ballast mass is kept invariable, therefore, as $h_{b}$ increases, the ballast density is modified accordingly and only the extra stiffness affects the results (red trace); on the other hand, as $h_{b}$ increases, the ballast density is kept unmodified and equal to its updated final value and the ballast layer mass increases proportionally, i.e., both the ballast added mass and stiffness are taken into account (black trace).
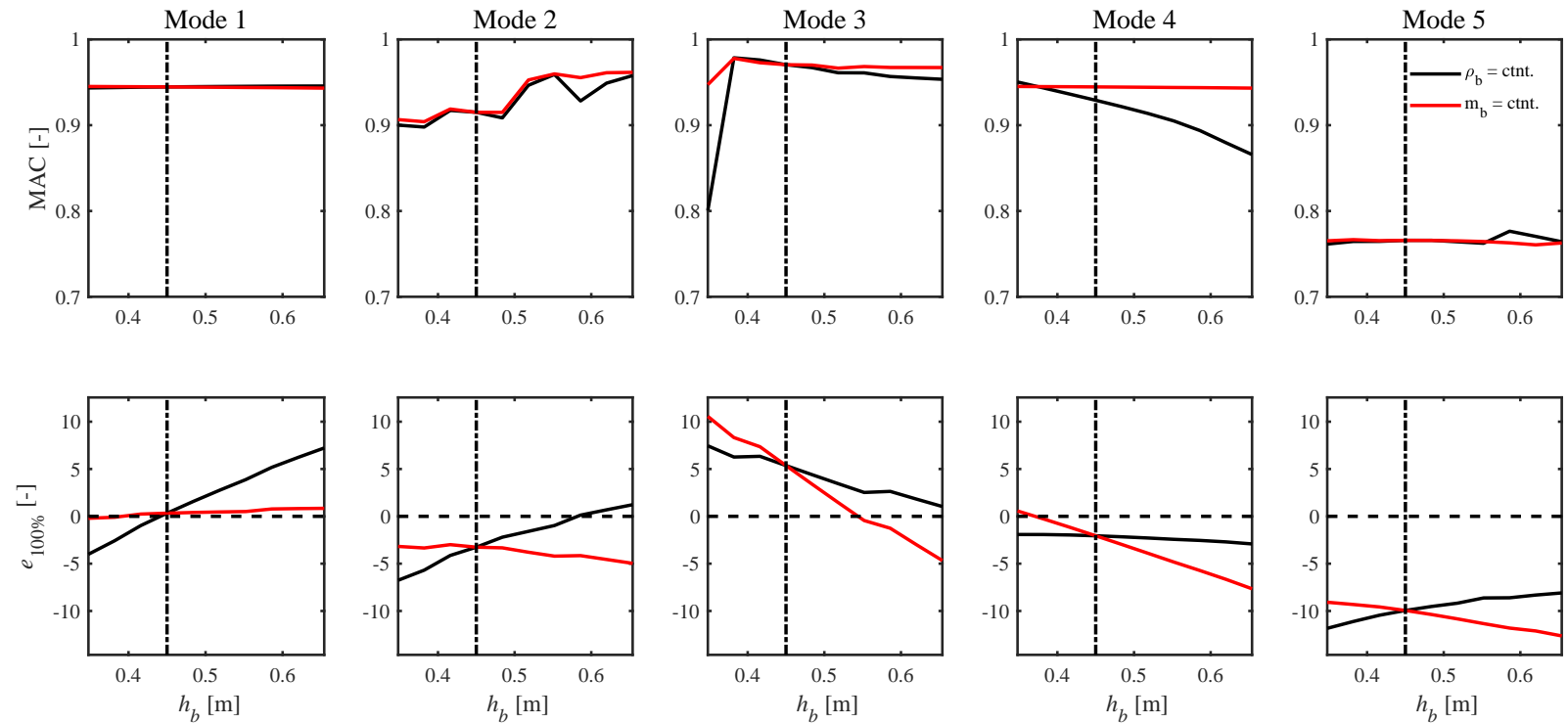

Figure 13: Modal parameters variation in terms of ballast thickness $h_{b}$. Red trace: constant ballast mass; black trace: real ballast mass.

In the case of the fundamental mode, the additional ballast provokes a reduction in the numerical frequency as a consequence of the added mass. The fundamental frequency is the one most affected by this factor. The mode-shape alteration is negligible in this case as it also is the contribution of the ballast added stiffness. The second (first torsion) mode evolution follows a similar trend, but the numerical frequency reduction is smaller and the effect of the added stiffness higher, when compared to the previous mode. The 
natural frequency of the third (transverse bending) mode increases with the thickness of the ballast layer due to the predominant effect of the added stiffness. The third mode-shape is only slightly modified. The influence of the ballast thickness on the fourth natural frequency (second torsion mode) is negligible, but the MAC number reduces remarkably. Finally, the fifth (second transverse bending) mode frequency reduces slightly as the height of the ballast layer increases, and the mode shape remains unaltered.

\section{Track-bridge interaction under train passages}

During the experimental campaign performed by the authors in 2019 the response of Old Guadiana Bridge was recorded under several train circulations. In this section the vertical acceleration at different sensors for four of these train passages is included, and an experimental-numerical comparison is presented.

Table 4 shows the axle scheme and load distribution of the passing trains, corresponding to the medium distance RENFE trains Altaria-9 and S449. Altaria 9-is a regular train made up of one Talgo 252 locomotive and 9 coaches with characteristic distance $d=13.14 \mathrm{~m}$ between shared axles. S449 has distributed traction and is formed by five cars: driver and passenger integrated cars at each end and three additional passenger coaches. In this case the distance between shared bogies $d=17.75 \mathrm{~m}$.

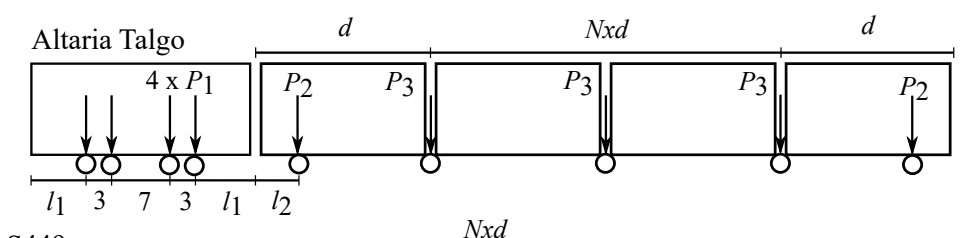

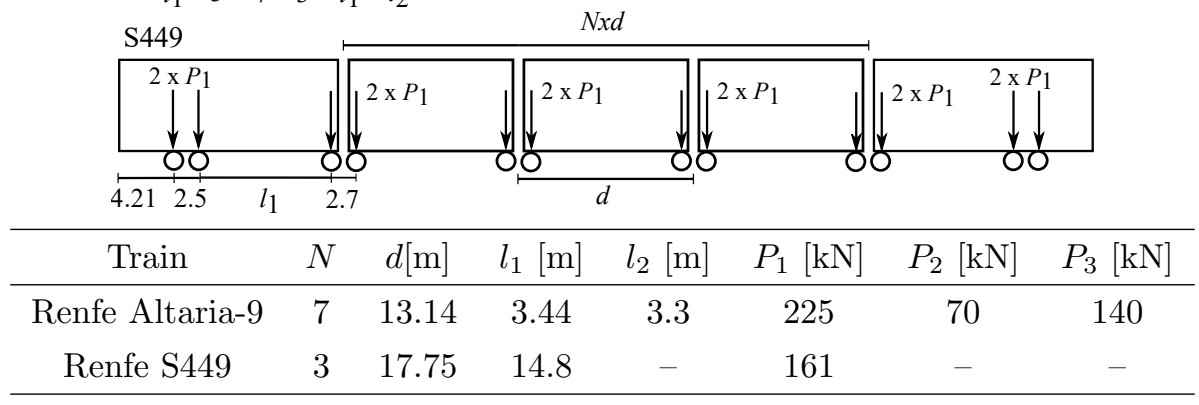

Table 4: Renfe medium distance Altaria-9 and S449 trains axle schemes.

The dynamic response of the bridge under two circulations per train type is discussed in this section, corresponding to passages along track 2 from Jaén to Madrid, and along track 1 in the opposite direction (see Fig. 3). Modal damping is also identified from $10 \mathrm{~s}$ of the free vibration response of the bridge recorded 
after the train passages. The modal damping ratios are obtained using the methodology presented by [41] to extract modal parameters using output-only responses. The amplitude of the bridge oscillations is in this case of the order of 100 times higher than under ambient vibration. In Table 5 the results are presented for each mode and train circulation $\left(\zeta_{i, F V}^{e x p}\right)$, average value for the four trains $\left(\bar{\zeta}_{i, F V}^{\text {exp }}\right)$ and compared to the ambient vibration values $\left(\zeta_{i, A V}^{\exp }\right)$. Free vibration damping levels are higher than values from ambient vibration for the first three modes. Nonetheless, the difference in the fundamental mode is moderate. Due to this and as it was not possible to identify damping for the fifth mode from the free vibration decay of the bridge, ambient vibration damping ratios are finally used in the subsequent numerical simulations for the first five modes.

\begin{tabular}{|c|c|c|c|c|c|c|c|c|}
\hline Train & $V[\mathrm{~km} / \mathrm{h}]$ & Track & Figure & $\zeta_{1, F V}^{\exp }[\%]$ & $\zeta_{2, F V}^{\exp }[\%]$ & $\zeta_{3, F V}^{\exp }[\%]$ & $\zeta_{4, F V}^{\exp }[\%]$ & $\zeta_{5, F V}^{\exp }[\%]$ \\
\hline Renfe Altaria 9 & 154,8 & 2 & 14 & 2,25 & 2,83 & 1,33 & 1,60 & - \\
\hline Renfe S449 & 154,8 & 1 & 15 & - & 2,58 & 1,59 & 1,52 & - \\
\hline Renfe S449 & 160,2 & 2 & 16 & 3,34 & 2,40 & 1,81 & 1,63 & - \\
\hline \multirow[t]{3}{*}{ Renfe S449 } & 157,5 & 1 & 17 & 2,84 & - & - & - & - \\
\hline & & & $\bar{\zeta}_{i, F V}^{\exp }[\%]$ & 2,81 & 2,60 & 1,57 & 1,58 & - \\
\hline & & & $\zeta_{i, A V}^{\exp }[\%]$ & 2,21 & 0,87 & 0,76 & 2,09 & 0,67 \\
\hline
\end{tabular}

Table 5: Identified damping ratios under free vibration (FV) and ambient vibration (AV).

Figs. 14 and 15 show the vertical acceleration under Altaria-9 train crossing the bridge along tracks 2 and 1 , respectively, at $155 \mathrm{~km} / \mathrm{h}$. Similarly, Figs. 16 and 17 represent the response for passages of the S449 train along track 2 at $160 \mathrm{~km} / \mathrm{h}$ and along track 1 at $158 \mathrm{~km} / \mathrm{h}$, respectively.

According to one of the characteristic distances of both trains $d$, that related to the length of the passenger coaches, the speed of Altaria-9 is close to the theoretical third resonant speed of the fundamental mode of Old Guadiana Bridge, $V_{1,3}=f_{1} \times d / 3=9.84 \times 13.14 \times 3.6 / 3=155.2 \mathrm{~km} / \mathrm{h}$. Also, the crossing speeds of S449 trains are in the vicinity of the theoretical fourth resonant speed of the fundamental mode, $V_{1,4}=f_{1} \times d / 4=9.84 \times 17.75 \times 3.6 / 4=157.2 \mathrm{~km} / \mathrm{h}$, and also close to a fifth resonant speed of the third mode, $V_{3,5}=f_{3} \times d / 5=12.84 \times 17.75 \times 3.6 / 5=164.1 \mathrm{~km} / \mathrm{h}$. Given the high resonance orders in the case of S449, a clear predominant contribution of these structural frequencies is not expectable. Furthermore, $L / d=0.67$ for this particular train (with $L$ being the span length). This ratio approaches the theoretical cancellation of the fourth resonance of the fundamental mode predicted in SS plates [10]. Even though the real bridge behaviour is not completely explained by the train axles scheme and the theoretical resonance and cancellation conditions, these ratios are helpful estimates for the interpretation of the results, and justify 
that the amplification at resonance of the fundamental mode excited by the $\mathrm{S} 449$ train should not be relevant.

In the first three figures (Figs. 14 16) the vertical acceleration is represented at sensors installed along mid-span of the first span (A2, A5, A8, A15, A17 and A18). Each row of the figures shows, respectively, the response at the centre of the loaded deck, centre of the unloaded deck, outer and inner borders of the loaded deck and finally, inner border of the unloaded deck. This allows a good comparison of the effects of the traffic direction and type of train in the response at equivalent positions. Fig. 17 shows the bridge acceleration at the centre of the second span (A13, A12), and at $x=L / 2$ and $x=3 L / 4$ in span 1 (A18, A16, A9). The response at each sensor and for each train is plotted in the time domain (first column), frequency domain (second column) and in one-third octave frequency bands (third column). In the upper left corner of the third column graphs, letters (L) and (U) differentiate sensors installed under the loaded or unloaded track, respectively. The experimental responses, represented in black trace, have been filtered applying two third-order Chebyshev filters with high-pass and low-pass frequencies of $1 \mathrm{~Hz}$ and $30 \mathrm{~Hz}$, respectively. The numerical acceleration response, in red trace, is computed by Modal Superposition. The dynamic equations of motion of the full FE model are transformed to modal space and numerically integrated by the Newmark-Linear Acceleration algorithm. The time-step is defined as 1/50 times the smallest period used in the analysis accounting for mode contributions up to $30 \mathrm{~Hz}$ as per European Standards 42 . 20 modes are included in the numerical analyses. Modal damping values identified during the experimental campaign under ambient vibration are assigned to the paired modes. For the rest of the modes EC recommended damping values are used. As for the train excitation, a constant moving load model is adopted, therefore neglecting vehicle-structure interaction (VBI) and track irregularity effects. This is a deliberate decision as (i) only the bridge response is of interest; (ii) VBI effects are mainly relevant at resonance [43]; (iii) trustworthy data for the S449 coaches suspension systems is not available at this point; (iv) one of the aims of the study is to assess the potential of the FE model implemented, including the ballasted track coupling, admitting modal superposition and using a moving load model, probable situation in engineering consultancies. Also, previous studies have shown that the effects of the track irregularities have a noticeable contribution on the vertical response of the vehicle itself and are perceptible in the soil far away from the track, being less important for the infrastructure at the bridge site [44 46]. The modal analysis is performed in 6 min with a Pentium i7-9700KF CPU 3.60 GHz RAM 64 GB and solving the dynamic equations for one train passage is done in $50 \mathrm{~s}$, approximately. 
The experimental response reveals maximum train-induced vibration levels of about $50 \%$ the Serviceability Limit State for traffic safety prescribed by EC [42] $\left(3.5 \mathrm{~m} / \mathrm{s}^{2}\right.$ for ballasted track bridges $)$. Altaria-9 train (Figs. 14 15) induces higher levels of vibration than S449 (Figs. 16 17), which can be partially explained by the travelling speed of Altaria-9 and the characteristic distance, approaching a third resonance of the fundamental mode of the bridge and the number of coaches. The experimental acceleration responses reveal also a noticeable coupling between the two decks that conform each span: Figs. 14 and 16 , corresponding to circulations along track 2, exhibit significant acceleration levels at points A17 and A15 (centre and inner border of the unloaded deck in span 1) when compared to the measurements at the same locations of the loaded deck (points A5 and A8, respectively). Also similar conclusions can be derived from Figs. 15 and 17 associated to passages along track 1, meaning that the transmission of vibrations between the loaded and unloaded decks through the ballast layer is substantial. This coupling effect is also bidirectional as can be derived from the observation of Figs. 14 and 15 corresponding to the passage of Altaria-9 at $155 \mathrm{~km} / \mathrm{h}$ in two opposite directions along different tracks. Very similar responses are measured at homologous points of the loaded and unloaded decks, independently of the traffic direction. The evident vibration transmission between the twin decks and the coupling detected in the lowest frequency modes justifies the need of a numerical model accounting for the continuity of the ballast in order to reproduce the real bridge response under passing trains.

The proposed numerical model is reasonably accurate, especially for frequency contents below $20 \mathrm{~Hz}$ and for the sensors installed at the loaded decks. The time-history responses show certain underestimation of the amplitude levels in the loaded decks in some cases during the forced vibration phase. Conversely, at the unloaded decks the predicted time history response during the forced vibration is overestimated under the passages of S449. The correspondence with the measurements improves during the free vibration phase. The frequency domain plots exhibit clear peaks at frequencies below $9 \mathrm{~Hz}$ associated to the excitation (i.e axle or bogie passing frequency, calculated as $V / d$ ) and their corresponding multiples, which are much more perceptible at the loaded sensors. These frequencies are well predicted by the numerical models, although the peak amplitudes are mildly overestimated at the unloaded deck sensors. The participation of several mode contributions corresponding to the lowest natural frequencies of the bridge are clearly distinguishable, especially under the circulation of S449. The correspondence in terms of frequency is accurate. Under the circulation of Altaria-9 train (Figs. 14 15) the contribution of the fundamental mode prevails and is generally underestimated by the numerical model in both the loaded and unloaded decks. From the previously said, 
the interaction with the vehicle suspension systems does not seem to play an important role for Altaria-9 trains. VBI tends to reduce the vibration levels on the structure and may become significant at resonance for train compositions with a high number of coaches when: (i) the frequency of the suspended masses of the vehicle approaches the natural frequency of the bridge; and (ii) the suspended mass is elevated compared to the bridge mass [43. For the S449, VBI should not be of importance either as clear resonance of the first bending mode is not induced.

The contribution of modes higher than the fundamental one are more visible under the passages of S449 shown in Figs. 16 17, which is in accordance with the observations about the speeds of circulation and the particular values of $L / d$ for both trains. The adequate prediction of these structural frequencies requires the consideration of the coupling effects between the decks through the ballast. In Fig. 16 it is noteworthy an amplification of the peak associated to the third mode of the bridge in the frequency spectrum for measurement points A2, A8 and A15 (outer, inner border of the loaded deck and inner border of the unloaded deck in span 1). This may be attributed to the fifth resonance of this mode, which is more perceptible at the sensor locations in which the transverse bending mode presents higher amplitude. This frequency contribution is present in the numerical predictions although the peak amplitude is better predicted at the loaded deck at points far from the inner border between the twin decks. The third mode of the structure was calibrated with a frequency difference $e_{100 \%}=5.3 \%$, which means that the numerical resonant speed of this mode is lower than the speed of the train. This can partially explain the lower contribution of the third mode in the numerical response in comparison to other frequencies. Finally, Fig. 17 shows acceleration responses at sensors not shown in the previous figures. At points A13 and A12 (centre of the second span of the loaded and unloaded decks, respectively) a number of peaks appear in the range 10-20 Hz in the frequency domain plots which could be associated to structural modes and also multiples of the bogie passing frequency. These frequencies are well predicted by the numerical model although slightly overestimated in the unloaded deck, as it is observed in all train passages. The level of accuracy of the model at other points different from mid-span is reasonable and slightly better predicted at the loaded deck, as depicted from the observation of the response at points A9 and A16.

As general conclusions, it can be said that (i) taking into account the ballasted track coupling between the decks is relevant in order to capture the contribution of modes higher than the first bending or first torsion modes under train passages; (ii) the energy dissipation associated to this coupling is amplitude 
dependent and its effect may be different depending on the train and the speed; (iii) the model presented herein reproduces with acceptable accuracy the bridge response both at the loaded and unloaded decks, but the correspondence is better in the former case; (iv) the solution of the dynamic problem is performed in reasonable time (less than $1 \mathrm{~min}$ ) with a personal computer once the modal analysis has been done; (vi) in this type of structures where the ballasted track coupling may be of importance, identifying the structure properties experimentally becomes essential. Finally, it should be stressed that the train excitation has been represented using a constant moving load model, therefore neglecting vehicle-structure interaction and the effect of track irregularities. This may influence the response of a short span bridge such as Old Guadiana, especially in the frequency range $30-60 \mathrm{~Hz}$, which may still have some effect on the stability of the ballast [47. Moreover, taking into account the simultaneous contribution of vehicle-structure and also soil-structure interaction, and separating those from the coupling exerted by the ballasted track on SS multi-deck bridges are proposed as interesting work lines for the future. 

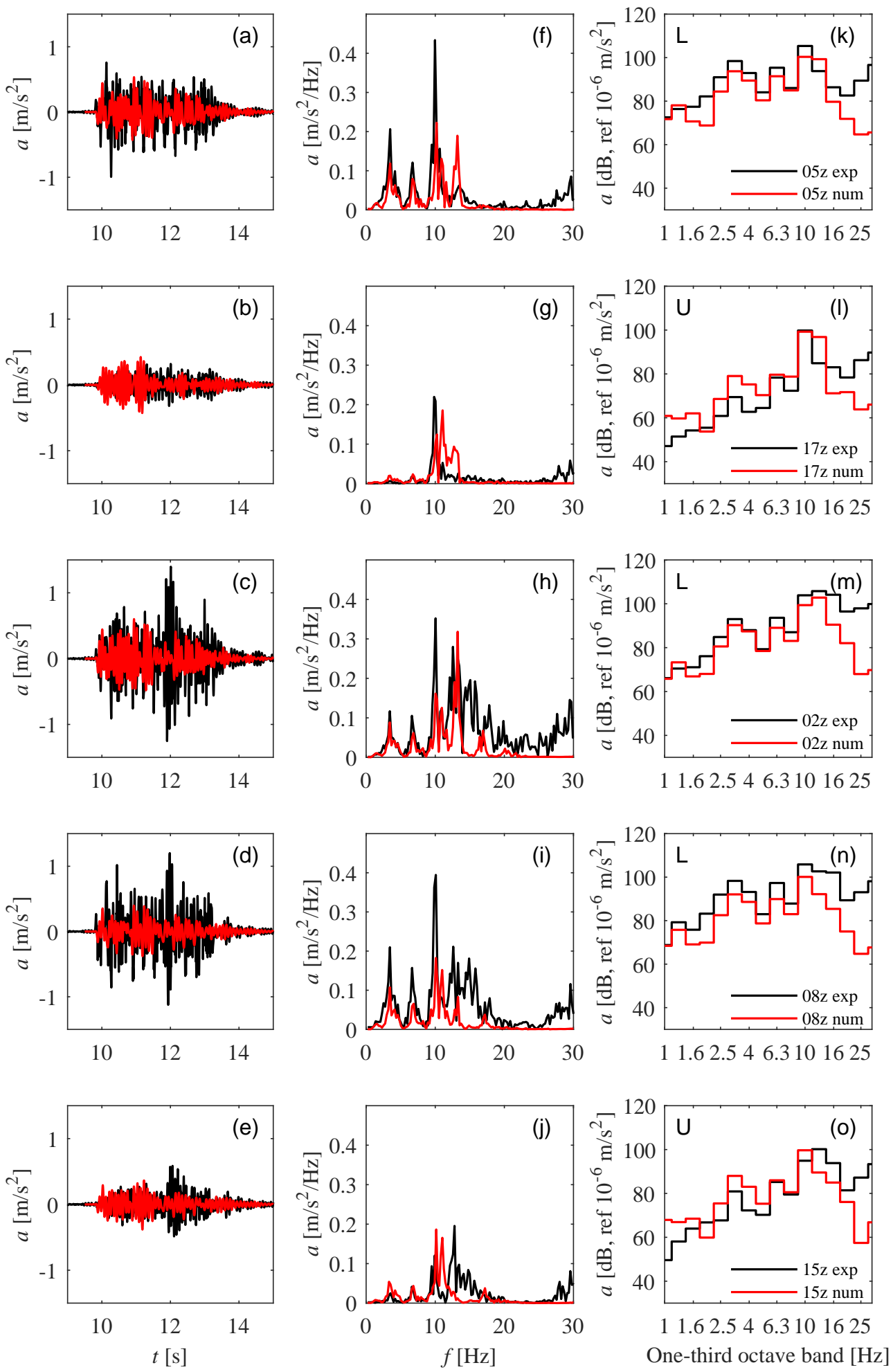

Figure 14: Time history (a-e), frequency content of the acceleration ( $\mathrm{f}-\mathrm{j}$ ) one-third octave band content of the acceleration (k-o) at points A5 A17 A2 A8 and A15, induced by Renfe Altaria-9 on track $2 \mathrm{~J}-\mathrm{M}$ at speed $V=154.8$ [km/h]. Experimental results (black line) vs numerical prediction (red line). 

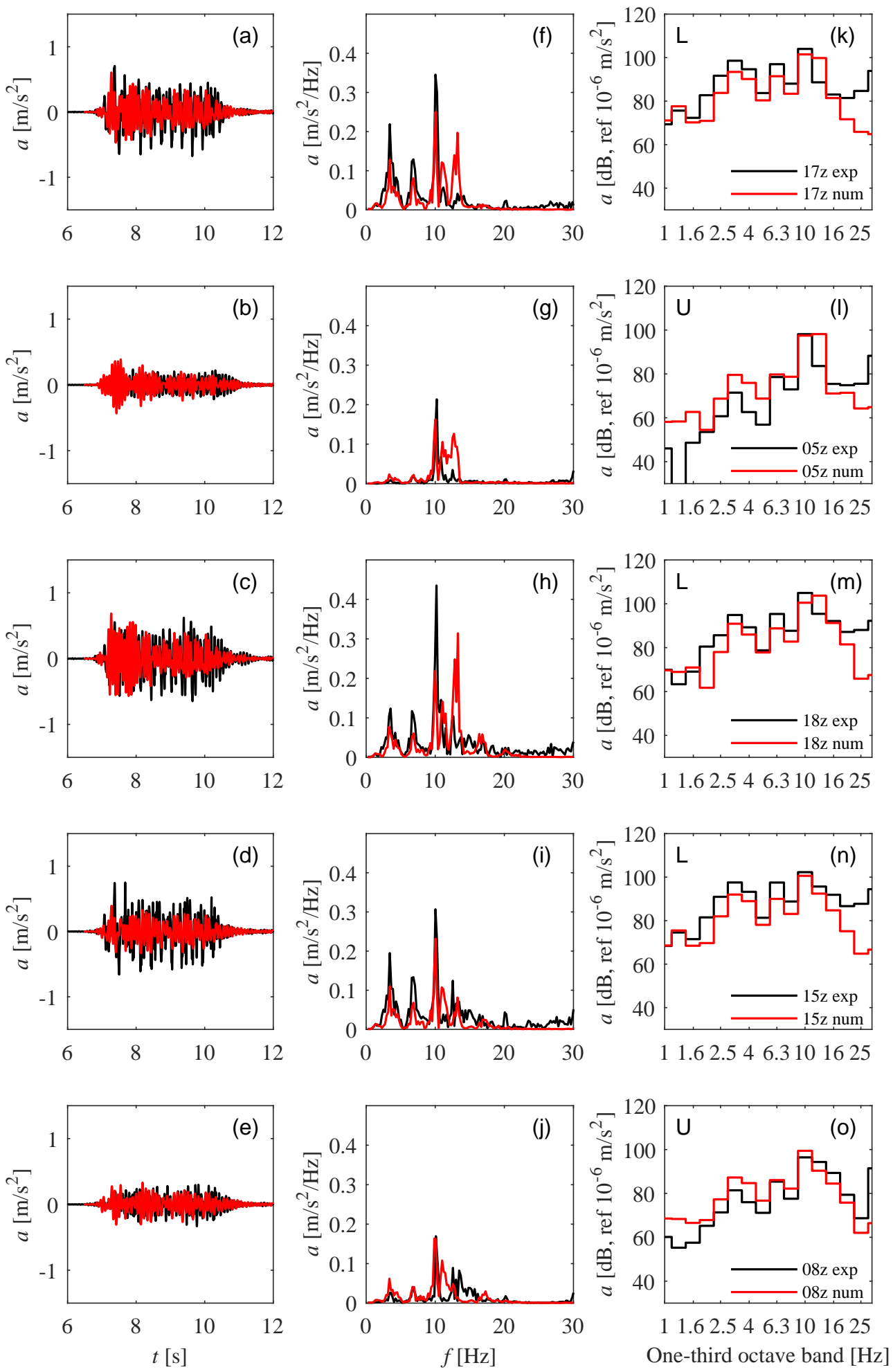

Figure 15: Time history (a-e), frequency content of the acceleration ( $\mathrm{f}-\mathrm{j}$ ) one-third octave band content of the acceleration (k-o) at points A17 A5 A18 A15 and A8, induced by Altaria-9 on track 1 M-J at speed $V=154.8$ [km/h]. Experimental results (black line) vs numerical prediction (red line). 

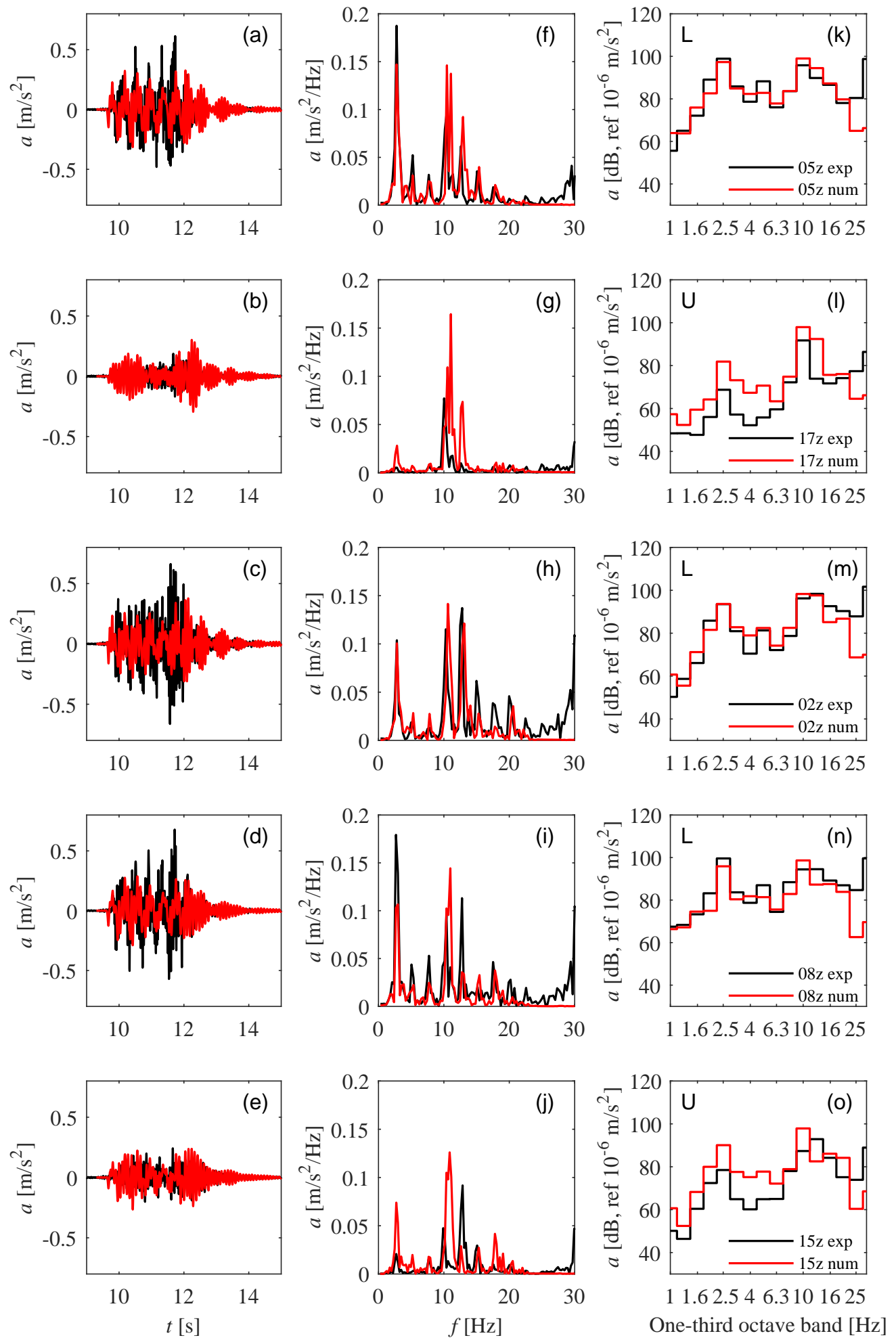

Figure 16: Time history (a-e), frequency content of the acceleration ( $\mathrm{f}-\mathrm{j}$ ) one-third octave band content of the acceleration (k-o) at points A5 A17 A2 A8 and A15, induced by S449 on track $2 \mathrm{~J}-\mathrm{M}$ at speed $V=160.2$ [km/h]. Experimental results (black line) vs numerical prediction (red line). Experiemntal results (black line) vs numerical prediction (red line). 

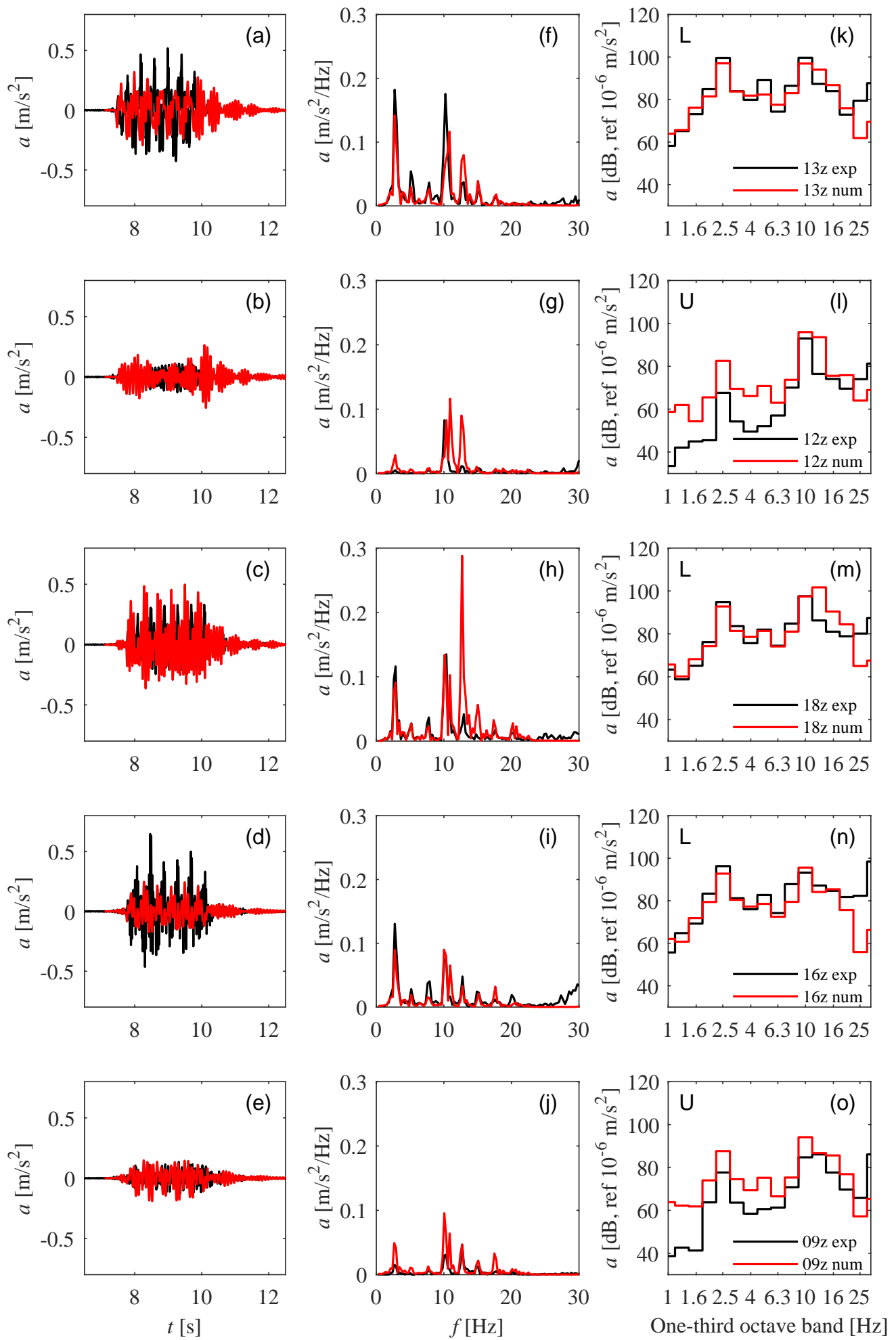

Figure 17: Time history (a-e), frequency content of the acceleration ( $\mathrm{f}-\mathrm{j}$ ) one-third octave band content of the acceleration (k-o) at points A13 A12 A18 A16 and A9, induced by S449 on track 1 M-J at speed $V=157.5$ [km/h]. Experimental results (black line) vs numerical prediction (red line). 


\section{Conclusions}

In this work the dynamic response of railway bridges composed by simply-supported spans and adjacent single-track decks weakly connected through the ballasted track is investigated considering ballast degradation due to the relative movements induced by railway traffic. With this purpose a 3D FE model of the track-bridge system is implemented and updated from experimental data. The degraded ballast is assumed as elastic and anisotropic at the regions between subsequent spans or adjacent decks.

The numerical model is able to represent the first five natural frequencies and mode-shapes identified experimentally with an average error in the frequencies close to $4 \%$ and an average MAC of 0.9 . In order for the model to reproduce experimental modes higher than the second one, it is essential to consider the coupling effect of the ballast layer, especially between the adjacent decks. Also, in order to be able to reproduce with reasonable accuracy the first five modes of the structure, considering the ballast along the shared border as a transversely isotropic material provides satisfactory results. In those areas the elastic moduli in the horizontal directions are updated to approximately $10 \%$ of the vertical elastic modulus.

Regarding the influence of the degraded ballast elastic properties on the modal parameters: (i) the first longitudinal bending mode is the one least affected; (ii) in order to obtain an acceptable error for the second mode natural frequency (first torsion mode) the elastic modulus in the horizontal directions $E_{b X}=E_{b Y}$ must be substantially lower than the vertical elastic modulus $E_{b Z}$, both along the longitudinal and along the transverse borders; (iii) the third mode (first transverse bending mode) is the one most affected by the degraded ballast elastic properties. A minimum value of the elastic modulus in the horizontal directions both between the decks and between the spans is needed for the numerical model to reproduce the experimental third mode, opposite to what happens with the torsion mode; and (iv) the fourth and fifth modes are most affected by the shear moduli in the vertical planes $G_{b X Z}=G_{b Y Z}$, the former between the adjacent decks and the latter between the two spans.

505

As per the structural response under railway traffic, the bridge exhibits a noticeable dynamic coupling between adjacent decks under operating conditions, which can be attributed to the continuity of the ballasted track. In general terms, the numerical-experimental correspondence is good for frequency contents up to $30 \mathrm{~Hz}$, although the numerical model predicts the vertical acceleration levels with more accuracy at the sensors installed at the loaded decks. At the unloaded decks the amplitudes associated to the excitation 
frequencies and to the lowest natural frequencies of the bridge are sometimes overestimated. In this type of structures where the ballasted track coupling may be of importance, identifying the structure properties experimentally becomes essential. Finally, analysing the extent of the ballast track-coupling effect on bridges of different lengths and typologies is proposed as an interesting future research line.

[6] Y. B. Yang, J. D. Yau, L. C. Hsu, Vibration of simple beams due to trains moving at high speeds, Engineering Structures 19 (11) (1997) 936-944.

[7] L. Frýba, A rough assessment of railway bridges for high speed trains, Engineering Structures 23 (5) (2001) 548-556. doi:\{10.1016/S0141-0296(00)00057-2\},

[8] J. D. Yau, Y. B. Yang, Vertical accelerations of simple beams due to successive loads traveling at resonant speeds, Journal Of Sound and Vibration 289 (1-2) (2006) 210-228. doi:\{10.1016/j.jsv.2005.02.037\}

[9] X. Q. Zhu, S. S. Law, Dynamic behavior of orthotropic rectangular plates under moving loads, Journal of Engineering Mechanics 129 (1) (2003) 79-87. doi:\{10.1061/(ASCE) 0733-9399(2003) 129:1(79)\}

[10] M. D. Martínez-Rodrigo, E. Moliner, A. Romero, G. De Roeck, P. Galvín, Maximum resonance and cancellation phenomena in orthotropic plates traversed by moving loads: Application to railway bridges, International Journal of Mechanical Sciences 169 .

[11] C. Rigueiro, C. Rebelo, L. Simões da Silva, Influence of ballast models in the dynamic response of railway viaducts, Journal of Sound and Vibration 329 (15) (2010) 3030 - 3040 
[12] C. Rebelo, M. Heiden, M. Pircher, L. Simões da Silva, Vibration measurements on existing single-span concrete railway viaducts in Austria, in: Soize, C and Schueller, GI (Ed.), Structural Dynamics - EURODYN 2005, Vols 1-3, Air France; Bouygues Travaux Publics; Ctr Sci \& Techn Batiment; Minist Delegue Rech; Muller BBM GmbH; Natl Tech Univ Athens; Stretto Messina SpA; Univ Marne Vallee, 2005, pp. 1637-1642, 6th International Conference on Structural Dynamics, Paris, FRANCE, SEP 04-07, 2005.

[13] C. Rebelo, L. Simões da Silva, C. Rigueiro, M. Pircher, Dynamic behaviour of twin single-span ballasted railway viaducts

- Field measurements and modal identification, Engineering Structures 30 (9) (2008) 2460-2469. doi:\{10.1016/j. engstruct.2008.01.023\}

[14] C. Rigueiro, C. Rebelo, L. Simões da Silva, Vibration of the railway track-viaduct system under moving vehicles taking into account the interaction effect, in: Sas, P and DeMunck, M (Ed.), proceedings of ISMA2006: International Conference on Noise and Vibration Engineering, vols 1-8, Katholieke Univ Leuven, Dept Mech Engn, 2006, pp. 1233-1247, International Conference on Noise and Vibration Engineering (ISMA2006), Louvain, BELGIUM, SEP 18-20, 2006.

[15] P. Galvín, A. Romero, E. Moliner, G. De Roeck, M. D. Martínez-Rodrigo, On the dynamic characterisation of railway bridges through experimental testing, Engineering Structures 226 (111261).

[16] T. Rauert, H. Bigelow, B. Hoffmeister, M. Feldmann, On the prediction of the interaction effect caused by continuous ballast on filler beam railway bridges by experimentally supported numerical studies Engineering Structures 32 (12) (2010) 3981 - 3988. doi:https://doi.org/10.1016/j.engstruct.2010.09.009 URL http://www.sciencedirect.com/science/article/pii/S0141029610003469

[17] K. Liu, G. Lombaert, G. De Roeck, Dynamic Analysis of Multispan Viaducts with Weak Coupling between Adjacent Spans, Journal of Bridge Engineering 19 (1) (2014) 83-90. doi:\{10.1061/(ASCE)BE.1943-5592.0000476\}

[18] W. M. Zhai, Z. L. Han, Z. W. Chen, L. Ling, S. Y. Zhu, Train-track-bridge dynamic interaction: a state-of-the-art review, Vehicle System Dynamics 57 (7) (2019) 984-1027. doi:10.1080/00423114.2019.1605085

[19] W. M. Zhai, K. Y. Wang, J. H. Lin, Modelling and experiment of railway ballast vibrations, Journal of Sound and Vibration 270 (4-5) (2004) 673-683.

[20] Y. S. Cheng, F. T. K. Au, Y. K. Cheung, Vibration of railway bridges under a moving train by using bridge-track-vehicle element, Engineering Structures 23 (12) (2001) 1597-1606.

[21] Y. B. Yang, J. D. Yau, Y. S. Wu, Vehicle-Bridge Interaction Dynamics. With Applications to High-Speed Railways, World Scientific.

[22] Z. H. Zhu, W. Gong, L. D. Wang, Y. Bai, Z. M. Yu, L. Zhang, Efficient assessment of 3D train-track-bridge interaction combining multi-time-step method and moving track technique, Engineering Structures 183 (2019) 290-302. doi:\{10. $1016 / j$.engstruct.2019.01.036

[23] L. Bonet, A. Andersson, J. Zwolski, J. M. Battini, Influence of the ballasted track on the dynamic properties of a truss railway bridge, Structure and Infraestructure Engineering 11 (6) (2015) 769-803. doi:10.1080/15732479.2014.912242.

[24] C. Costa, D. Ribeiro, P. Jorge, R. Silva, R. Calçada, A. Arede, Calibration of the numerical model of a short-span masonry railway bridge based on experimental modal parameters, in: Moreira, PMGP and Tavares, PJ (Ed.), ICSI 2015 The 1st International Conference on Structural Integrity Funchal, Vol. 114 of Procedia Engineering, European Struct Integr Soc, Portuguese Natl Comm, 2015, pp. 846-853, 1st International Conference on Structural Integrity (ICSI), Funchal, PORTUGAL, SEP 01-04, 2015. doi:\{10.1016/j.proeng.2015.08.038\}

[25] J. Malveiro, D. Ribeiro, C. Sousa, R. Calçada, Model updating of a dynamic model of a composite steel-concrete railway 
viaduct based on experimental tests, Engineering Structures 164 (2018) 40-52. doi:\{10.1016/j.engstruct.2018.02.057\}

[26] G. Chellini, L. Nardini, W. Salvatore, Dynamical identification and modelling of steel-concrete composite high-speed railway bridges, Structure and Infrastructure Engineering 7 (11) (2011) 823-841. doi:\{10.1080/15732470903017240\}

[27] L. R. Ticona Melo, D. Ribeiro, R. Calçada, T. N. Bittencourt, Validation of a vertical train-track-bridge dynamic interaction model based on limited experimental data, Structure and Infrastructure Engineering 16 (1, SI) (2020) 181-201. doi: $\{10.1080 / 15732479.2019 .1605394\}$

[28] C. Bonifácio, D. Ribeiro, R. Calçada, R. Delgado, Dynamic behaviour of a short span filler-beam railway bridge under high-speed traffic, in: Proc. 2nd Int. Conf. on Railway Technology: Research, Development and Maintenance, 2014.

[29] Y. Guo, C. Zhao, V. Markine, G. Jing, W. Zhai, Calibration for discrete element modelling of railway ballast: A review, Transportation Geotechnics 23 (2020) 100341.

[30] H. Huang, S. Chrismer, Discrete element modeling of ballast settlement under trains moving at critical speeds, Construction and Building Materials 38 (2013) 994-1000, 25th Anniversary Session for ACI 228 Building on the Past for the Future of NDT of Concrete.

[31] P. Lou, A vehicle-track-bridge interaction element considering vehicle's pitching effect, Finite Elements in Analysis and Design 41 (4) (2005) 397-427.

[32] R. A. Clark, P. A. Dean, J. A. Elkins, S. G. Newton, An investigation into the dynamic effects of railway vehicles running on corrugated rails, Journal of Mechanical Engineering Science 24 (2) (1982) 65-76.

[33] CITEF, Informe sobre resultado de registros en puente sobre Río Guadiana P.K. 160.000. Línea Madrid-Cádiz, tramo Alcázar de San Juan-Manzanares.

[34] R. J. Allemang, The modal assurance criterion - twenty years of use and abuse, Journal of Sound and Vibration (37) (2003) 14-21.

[35] J. Haataja, Matlab function for simulating a simple real-coded genetic algorithm, Center for Scientific Computing, Box 405, FIN- 02101 Espoo. Internet: Juha.Haataja@csc.fi, 2000.

[36] Ministerio de Fomento, Gobierno de España, IF3 - Instrucción para el proyecto y construcción de obras ferroviarias, 2015.

[37] J. Malveiro, D. Ribeiro, R. Calçada, R. Delgado, Updating and validation of the dynamic model of a railway viaduct

ㅁ with precast deck Structure and Infrastructure Engineering 10 (11) (2014) 1484-1509. arXiv:https://doi.org/10.1080/ 15732479.2013.833950, doi:10.1080/15732479.2013.833950 URL https://doi.org/10.1080/15732479.2013.833950

[38] UNE-EN 13674-1:2006, Railway applications - track - rail - part 1: Vignole railway rails 46 kg/m and above, Spanish Norm CTN 25 - APLICACIONES FERROVIARIAS, Asociación Española de Normalización y Certificación, AENOR (2006).

[39] K. Nguyen, J. M. Goicolea, F. Galbadón, Comparison of dynamic effects of high-speed traffic load on ballasted track using a simplified two-dimensional and full three-dimensional model Proceedings of the Institution of Mechanical Engineers, Part F: Journal of Rail and Rapid Transit 228 (2) (2014) 128-142. arXiv:https://doi.org/10.1177/0954409712465710. doi:10.1177/0954409712465710

URL https://doi .org/10.1177/0954409712465710

[40] Ministerio de Fomento, Gobierno de España, IAPF 2010 - Instrucción de acciones a considerar en el proyecto de puentes de ferrocarril, 2010.

[41] B. Kim, N. Stubbs, T. Park, A new method to extract modal parameters using output-only responses, Journal of Sound and Vibration 282 (1) (2005) 215-230. 
[42] CEN/TC250, Eurocode: Basis of structural design. Annex A2: Application for bridges. Final version, European Committee for Standardization, Brussels, 2005.

[43] A. Doménech, P. Museros, M. D. Martínez-Rodrigo, Influence of the vehicle model on the prediction of the maximum bending response of simply-supported bridges under high-speed railway traffic, Engineering Structures 72 (2014) $123-139$.

[44] A. Romero, P. Galvín, J. Domínguez, Comportamiento dinámico de viaductos cortos considerando la interacción vehículovía-estructura-suelo, Revista Internacional de Métodos numéricos para Cálculo y Diseño en Ingeniería 28(1) (2012) 55-63.

[45] M. A. Peixer, P. A. Montenegro, H. Carvalho, D. Ribeiro, T. N. Bittencourt, R. Calçada, Running safety evaluation of a train moving over a high-speed railway viaduct under different track conditions, Engineering Failure Analysis 121 (2021) 105133.

[46] A. Romero, M. Solís, J. Domínguez, P. Galvín, Soil-structure interaction in resonant railway bridges, Soil Dynamics and Earthquake Engineering (47) (2013) 108-116.

[47] M. Zacher, M. Baebler, Dynamic behaviour of ballast on railway bridges, in: Dynamics of High-Speed railway bridges, Faculdade de Engenharia da Universidade do Porto, 2005. 